\title{
Gender differences in murine pulmonary responses elicited by cellulose nanocrystals
}

\author{
Anna A. Shvedova ${ }^{1,3^{*}}$, Elena R. Kisin ${ }^{1}$, Naveena Yanamala', Mariana T. Farcas ${ }^{1}$, Autumn L. Menas ${ }^{1}$, \\ Andrew Williams ${ }^{4}$, Philip M. Fournier ${ }^{5}$, Jeffrey S. Reynolds ${ }^{2}$, Dmitriy W. Gutkin ${ }^{6}$, Alexander Star ${ }^{5}$, Richard S. Reiner ${ }^{7}$, \\ Sabina Halappanavar ${ }^{4}$ and Valerian E. Kagan ${ }^{8,9}$
}

\begin{abstract}
Background: Cellulose-based materials have been used for centuries to manufacture different goods derived from forestry and agricultural sources. In the growing field of nanocellulose applications, its uniquely engineered properties are instrumental for inventive products coming to competitive markets. Due to their high aspect ratio and stiffness, it is speculated that cellulose nanocrystals (CNC) may cause similar pulmonary toxicity as carbon nanotubes and asbestos, thus posing a potential negative impact on public health and the environment.

Methods: The present study was undertaken to investigate the pulmonary outcomes induced by repeated exposure to respirable CNC. C57BL/6 female and male mice were exposed by pharyngeal aspiration to CNC (40 $\mathrm{\mu g} /$ mouse) 2 times a week for 3 weeks. Several biochemical endpoints and pathophysiological outcomes along with gene expression changes were evaluated and compared in the lungs of male and female mice.

Results: Exposure to respirable CNC caused pulmonary inflammation and damage, induced oxidative stress, elevated TGF- $\beta$ and collagen levels in lung, and impaired pulmonary functions. Notably, these effects were markedly more pronounced in females compared to male mice. Moreover, sex differences in responses to pulmonary exposure to CNC were also detected at the level of global mRNA expression as well as in inflammatory cytokine/chemokine activity.
\end{abstract}

Conclusions: Overall, our results indicate that there are considerable differences in responses to respirable CNC based on gender with a higher pulmonary toxicity observed in female mice.

Keywords: Cellulose, Gender differences, Pulmonary toxicity, Inflammation, Oxidative stress, mRNA expression

\section{Background}

Cellulose-based materials have been used for centuries to manufacture a number of different goods derived from forestry and agricultural sources (wood, hemp, cotton, flax plants, etc.). In the increasingly growing field of cellulose applications, their uniquely engineered properties (e.g. mechanical, thermal, rheological and optical) are instrumental for inventive products coming to competitive market. High consumer demand, industrial growth, and government regulation/funding challenges the production of contemporary goods derived from

\footnotetext{
*Correspondence: ats1@cdc.gov

'Health Effects Laboratory Division, NIOSH, Exposure Assessment Branch, 1095 Willowdale Road, Morgantown, WV 26505, USA

${ }^{3}$ Department of Physiology \& Pharmacology, School of Medicine/MVU,

Morgantown, WV, USA

Full list of author information is available at the end of the article
}

sustainable and renewable sources. These technologically advanced materials must also meet safety standards of low environmental impact and negative health effects to animals/humans [1].

Cellulose is the most abundant organic constituent produced by plants and tunicates and is the major structural component in plant cells and tissues. Cellulose is a long chain natural polymer that plays an essential role in the human food cycle. Cellulose has many applications in industry including building insulation, veterinary foods, additive in plastics/coatings, wood and paper, fibers and clothes, cosmetics and pharmaceutical industries [2]. Nanocellulose (NC) is produced from a variety of cellulose sources, either by hydrolysis $[3,4]$ or oxidation [5], giving rise to nanocrystalline structures with different dimensions and surface chemistries. Cellulose 
nanowhiskers or nanocrystals $(\mathrm{CNC})$ are a crystalline form of NC produced by acid hydrolysis of cellulose fibers employing either sulfuric or hydrochloric acid. $\mathrm{CNC}$ are rod-like, highly crystalline particles (relative crystallinity index above $75 \%$ ) with a rectangular cross section. Their dimensions depend on the intrinsic cellulose source, hydrolysis and temperature. $\mathrm{CNC}$ used in this study are produced by the treatment of wood pulp with $64 \%$ sulfuric acid. This hydrolyzes the amorphous entity of the cellulose polymer yielding an acid resistant $\mathrm{CNC}$ product. Due to their unique physical/chemical characteristics, many other potential applications exist for $\mathrm{CNC}$ including a variety of coatings, packaging, rheological modifiers, and reinforcing agents in nanocomposites. CNCs may also be utilized in the production of detergents, transparent materials for the military (including a wide range of defense-related applications, lightweight transparent armor, eye protection and face shields), multiphase compositions to stabilize aqueous paint mixtures, personal care products (shampoos, detergents, conditioners), and as texturing agent in food industry (ice-creams and whip cream substitutes).

It has been previously reported that pulmonary exposure of rats to cellulose fibers (CF) caused hyperplasia and mild interstitial fibrosis of alveolar cells. Low soluble $\mathrm{CF}$ are not efficiently cleared from the animal lungs thus causing long bio-persistent effects [6-10]. In workers exposed to cellulose, there was a higher prevalence of respiratory symptoms and asthmatic episodes, with a decrease in pulmonary function [11-14]. Ericsson et al (1988) have reported an increase in the prevalence of upper respiratory tract outcomes that are dose dependent, while Thorén et al, $(1989,1994)$ described an increased risk for asthma and chronic obstructive pulmonary diseases in workers from paper mills. Due to the high frequency of respiratory symptoms, a reduction of exposure to cellulose dust was recommended [15]. As of today, there are limited studies available documenting pulmonary toxicity of cellulose based nanomaterials, in particular CNCs. We have previously reported that short term exposure of $\mathrm{C} 57 \mathrm{BL} / 6$ mice to respirable $\mathrm{CNC}$ caused pulmonary damage, accelerated oxidative stress, acute pulmonary inflammation with accelerated recruitment of macrophages, neutrophils, lymphocytes and eosinophils found in bronchial alveolar lavage fluids (BAL) $24 \mathrm{~h}$ post treatment [16].

Gender dissimilarities in airway responses, the lung's mechanical properties, and the clinical manifestations of pulmonary disease are observed throughout the human life span and are related to biological - as well as sociocultural - factors [17-23]. Sex differences in the incidence and prognosis of a number of respiratory diseases have been reported [17]. It has been shown that women are at an increased risk of adverse health outcomes elicited by air pollution and smoking compared to men $[18,19]$. Higher rates of maladies and mortality was also noted in females exposed to ozone and other gaseous pollutants-leading to lung inflammation/injury, loss of immune function, and an increased risk of respiratory infection [22, 23].

The present study was undertaken to investigate the pulmonary outcomes induced by repeated exposure to respirable $\mathrm{CNC}$. $\mathrm{C} 57 \mathrm{BL} / 6$ female and male mice were treated by pharyngeal aspiration with CNC ( $40 \mu \mathrm{g} /$ mouse) 2 times a week for 3 weeks. The primary goal of this study was to determine whether gender affects pulmonary function, global mRNA expression, and cytokine/chemokine inflammatory responses in the lung of C57BL/6 mice. This was achieved by comparison of pulmonary function, pathology outcomes, lung injury and inflammatory responses, oxidative stress bio-markers, gene ontology, pathway analysis, prediction of upstream regulatory transcription factors in lungs of male and female mice. The results presented herein clearly indicate considerable gender differences in response to respirable $\mathrm{CNC}$ with a higher rate of pulmonary toxicity observed in female mice.

\section{Methods \\ CNC characterization}

$\mathrm{CNC}$ solutions were prepared by suspending the asreceived solid samples in water. Atomic force microscopy (AFM) samples were prepared by drop casting $5 \mu \mathrm{L}$ of $20 \mathrm{mg} / \mathrm{L}$ sample solution on freshly cleaved mica. AFM analysis was conducted using a Multimode scanning probe microscope (Veeco Instruments Inc., Waltham MA) in tapping mode. An ACL probe (AppNano, Mountain View, CA) was utilized at a frequency between $160-225 \mathrm{kHz}$, an amplitude set point between $1.5-1.8 \mathrm{~V}$, and a drive amplitude between $100-300 \mathrm{mV}$. The resulting images were processed using Gwyddion (Brno Czech Republic). Dynamic light scattering analysis (DLS) was performed using a Brookhaven Instrument Corporation ZetaPALS (Holtsville, NY). 10 runs were averaged using an assumed refractive index of 1.474 (real). Scanning electron microscopy (SEM) samples were prepared by drop casting $5 \mu \mathrm{L}$ of $2 \mathrm{~g} / \mathrm{L}$ sample solution on a silicon wafer that had been treated with piranha solution (7:3 concentrated $\mathrm{H}_{2} \mathrm{SO}_{4}: 30 \% \mathrm{H}_{2} \mathrm{O}_{2}$ at $70{ }^{\circ} \mathrm{C}$ ) for $30 \mathrm{~min}$ immediately before sample deposition. SEM and energy dispersive X-ray spectroscopy (EDX) was performed on an FEI XL-30 F field emission SEM, which was operated at a beam voltage of $10 \mathrm{kV}$ and equipped with an EDAX energy dispersive system. Zeta potential of the nanocellulose material was measured using the same Brookhaven Instrument Corporation ZetaPALS (Holtsville, $\mathrm{NY}$ ) utilized for DLS. A $1 \mathrm{~g} / \mathrm{L}$ aqueous sample (stock solution) was tested. 


\section{Animals}

Specific pathogen-free adult male and female C57BL/6 mice (7-8 weeks) were supplied by Jackson Laboratories (Bar Harbor, ME) and weighed $20.0 \pm 1.9 \mathrm{~g}$ when used. Animals were housed individually (one mouse per cage) receiving filtered high efficiency particulate air (HEPA) in the Association for Assessment and Accreditation of Laboratory Animal Care (AAALAC), Internationalaccredited National Institute of Occupational and Safety Health (NIOSH) animal facility. All animals were acclimatized in the animal facility under controlled temperature and humidity environment with a $12 \mathrm{~h}$ light/dark cycle for one week prior to use. Beta Chips (Northeastern Products Corp., Warrensburg, NY) were used for bedding and changed weekly. Animals were supplied with water and certified chow 7913 (Harlan Teklad, Indianapolis, IN) ad libitum, in accordance with the guidelines and policy of the Institute of Laboratory Animal Resources, National Research Council. All procedures in the study comply with the ethical standards set forth by the Animal Welfare Act (enforced by the United States Department of Agriculture) and the Office of Laboratory Animal Welfare (OLAW). The studies were approved by the NIOSH Health Effects Laboratory Division (HELD) Institutional Animal Care and Use Committee within the Center for Disease Control (Public Health Services Assurance Number A4367-01) in accordance with an approved institutional animal protocol (protocol number 13-AS-M019).

\section{General experimental design}

To assess pulmonary toxicity, mice were treated by repeated pharyngeal aspiration with suspensions of CNC (40 $\mathrm{\mu g} / \mathrm{mouse} /$ day) in United States Pharmacopeia (USP) sterile water (Hospira Inc, USA). The corresponding control mice were administered USP sterile water. Mice were exposed twice a week for three consecutive weeks to obtain a cumulative dose of $240 \mu \mathrm{g} /$ mouse of CNC. Animals were weighed and sacrificed 3 month following their last exposure. Specifically, human equivalent workplace exposure to a deposited cumulative dose of $240 \mu \mathrm{g}$ of $\mathrm{CNC}$ can be achieved in $\sim 42$ working days at allowable exposure limits ( $5 \mathrm{mg} / \mathrm{m}^{3}$ of cellulose) defined by Occupational Safety \& Health Administration (OSHA). These calculations were performed using the formula published previously by our group [24]. Briefly, the human equivalent exposure time periods required for acquiring an equivalent deposited dose as employed in this study were estimated by using alveolar lung surface areas of $102 \mathrm{~m}^{2}$ for human [25] and $0.06 \mathrm{~m}^{2}$ for mouse [26]. Other values used for these estimations included $9.6 \mathrm{~m}^{3}$ 8-h air intake [27]; and alveolar deposition fraction based on aerodynamic particle size. The $\mathrm{T}_{1 / 2}$ for clearance in humans is $\sim 1$ year and can be ignored from these estimations, as the clearance would be insignificant over the 42 days required to achieve an equivalent worker lung burden.

\section{Preparation and administration of CNC}

Wood pulp derived CNC (freeze dried (powder form) samples) were provided by Forest Products Laboratory (FPL, United States Forest Service, Madison, WI). CNC was produced from machine-dried prehydrolysis kraft rayon-grade dissolving wood pulp by hydrolysis with $64 \%$ sulfuric acid at $45{ }^{\circ} \mathrm{C}$ for $90 \mathrm{~min}$, followed by dilution, neutralization of the acid with $\mathrm{NaOH}$, and membrane filtration [28]. Commercial dissolving pulp (50 kg) as drylap is stripcut and packed into a $400 \mathrm{~L}$ glass-lined reactor. Under vacuum, $300 \mathrm{~L}$ of $64 \%$ (PC-grade) sulfuric acid (Columbus Chemical Industries, Columbus, WI) already warmed to $45^{\circ} \mathrm{C}$ is sprayed onto the cellulose over $15 \mathrm{~min}$ while stirring begins. After a total of $90 \mathrm{~min}$ at $45{ }^{\circ} \mathrm{C}$, the reaction is quenched by dilution into $1200 \mathrm{~L}$ reverse osmosis (RO) water in a $6500 \mathrm{~L}$ glass-lined reactor. About $1 \mathrm{~kg}$ of (80 \% technical-grade) sodium chlorite (Alfa Aesar, Ward Hill, MA) is added and stirred for a half hour. Residual chlorine dioxide is swept from the reactor headspace with a scrubber. The sulfuric acid is neutralized with $8 \%$ sodium hydroxide solution, via the dilution of about $300 \mathrm{~L}$ of $50 \%$ (FCCgrade) sodium hydroxide (Columbus Chemical Industries, Columbus, WI). The aggregated CNC suspension is circulated in a tubular ultrafiltration membrane (200,000 Dalton) system for about $40 \mathrm{~h}$ displacing sodium sulfate solution with $\mathrm{RO}$ water. The $\mathrm{CNC}$, now a colloidal suspension, is then passed through a 20 micron filter before the ultrafiltration system is used to concentrate the purified CNC to $12 \%$ solids (54\% yield) for cold storage. Some of the CNC suspension is diluted to $1 \%$ solids into which another tenth by volume of reclaimed (85\%) tert-butanol (Aldrich, Milwaukee, WI) is mixed. This mixture is partially frozen in a commercial ice-cream machine, spread into trays then frozen solid prior to freeze drying.

Stock suspension of CNC for animal studies was prepared in USP grade water with $\mathrm{pH}$ adjusted to 7.0. The samples were sonicated for $2 \mathrm{~min}$ with a probe sonicator (Branson Sonifier 450, $10 \mathrm{~W}$ continuous outputs) and then sterilized by autoclaving. These stock suspensions were further diluted prior to animal exposures. Endotoxin levels in all used CNC samples were below the detection limit $(0.01 \mathrm{EU} / \mathrm{ml})$ as was assessed by a Limulus amebocyte lysate (LAL) chromogenic endpoint assay kit (Hycult biotech, Inc., Plymouth Meeting, PA).

Mouse pharyngeal aspiration was used for $\mathrm{CNC}$ administration. This technique has been reported to provide widespread delivery of particles to the deep lung and to be highly correlated with the administered dose 
[29]. Briefly, after anesthesia with a mixture of ketamine (Phoenix, St. Joseph, MO) and xylazine (Phoenix, St. Joseph, MO) (62.5 and $2.5 \mathrm{mg} / \mathrm{kg}$ subcutaneous in the abdominal area), the mouse was placed on a board in a near vertical position and the animal's tongue was extended with lined forceps. A suspension of cellulose (40 $\mathrm{\mu g} /$ mouse) was placed posterior in the throat and the tongue held until the suspension was aspirated into the lungs. The exposure regime was repeated twice a week (Monday and Thursdays of the week @ 9 am) for three consecutive weeks. All mice from the control and $\mathrm{CNC}$ treated groups survived this exposure procedure and exhibited no overt behavioral or health outcomes.

\section{Obtaining bronchoalveolar lavage (BAL)}

Mice were weighed and sacrificed 3 month post-CNC exposure with intraperitoneal injection of sodium pentobarbital $(>100 \mathrm{mg} / \mathrm{kg})$ and exsanguinated. The trachea was cannulated with a blunted 22-gauge needle, and BAL was performed using cold sterile PBS at a volume of $0.9 \mathrm{ml}$ for the first lavage (kept separate) and $1.0 \mathrm{ml}$ for the subsequent lavages. Approximately $5.0 \mathrm{ml}$ of BAL fluid per mouse was collected in sterile $15 \mathrm{~mL}$ falcon tubes (Becton Dickinson Labware, Franklin Lakes, NJ). Pooled BAL cells for each individual mouse were washed in $\mathrm{PBS}$ by centrifugation $\left(800 \mathrm{X} \mathrm{g}\right.$ for $10 \mathrm{~min}$ at $4{ }^{\circ} \mathrm{C}$ ). Cell-free, first-fraction BAL aliquots were used immediately for lactate dehydrogenase (LDH) assays, whereas the remainder was frozen at $-80{ }^{\circ} \mathrm{C}$ until processed.

\section{BAL cell counting and differentials}

The degree of inflammatory response induced by repeated $\mathrm{CNC}$ exposure was estimated by quantifying total cells, alveolar macrophages (AMs), polymorphonuclear leukocytes (PMNs), lymphocytes and eosinophils in the BAL. Cell counts were performed using an electronic cell counter equipped with a cell sizing attachment (Coulter model Multisizer II with a 256C channelizer, Coulter Electronics, Hialeah, FL). The cells were identified by their characteristic cell shape in cytospin preparations stained with HEMA 3 solution I, solution II and fixative (Fisher Scientific, Kalamazoo, MI), and differential counts of BAL cells was carried out. At least 300 cells per slide were considered for each sample for this examination. Additionally, quantitative assessment of giant multi-nucleated cells in BAL was performed. Blind-coded slides were independently scored by two readers. At least 2000 cells per slide were considered for each sample for this analysis.

\section{Preparation of lung homogenates}

The whole mouse lung were separated from other tissues and weighed before being homogenized with a tissue tearer (model 985-370, Biospec Products Inc., Racine, WI) in PBS (pH 7.4) for approximately 2 min. The homogenate suspensions were aliquoted and stored at $-80{ }^{\circ} \mathrm{C}$ until processed.

\section{Lung histopathology}

Lung tissues were harvested and inflation fixed in situ with $4 \%$ paraformaldehyde at constant pressure of $10 \mathrm{~cm} \mathrm{H}_{2} \mathrm{O}$ for $10 \mathrm{~min}$ with the chest cavity open. Coronal sections were cut from the lungs, embedded in paraffin, and sectioned at a thickness of $5 \mu \mathrm{m}$ with an HM 320 rotary microtome (Carl Zeiss, Thornwood, NY). Prepared sections were then stained with hematoxylin and eosin (H\&E), and histological evaluation was performed. Sample identification was coded to ensure unbiased evaluation.

\section{Total protein activity and lactate dehydrogenase (LDH) release}

Measurement of total protein in the BAL fluid and lung homogenates was performed using a modified Bradford assay according to the manufacturer's instructions (Bio-Rad, Hercules, CA) with bovine serum albumin as the standard control. The activity of LDH was assayed spectrophotometrically using a Synergy H1 Hybrid Reader (BioTek, Winooski, VT) at $340 \mathrm{~nm}$. The reduction of nicotinamide adenine dinucleotide in the presence of lactate using a Lactate Dehydrogenase Reagent Set (Pointe Scientific, Lincoln Park, MI) was monitored.

\section{Myeloperoxidase (MPO) activity}

Inflammatory response in the lung of mice after repeated exposure to $\mathrm{CNC}$ was assessed by measurement of MPO in lung homogenates using commercially available enzyme-linked immunosorbent assay (ELISA) colorimetric assay (Northwest Life Science Specialties, LLC, Vancouver, WA). Results for MPO activity were normalized to total protein content in tissue homogenate samples.

\section{Evaluation of oxidative stress biomarkers}

Oxidative damage to the lung following repeated $\mathrm{CNC}$ exposure was evaluated by the presence of lipid peroxidation products, protein carbonyls, vitamin $\mathrm{E}$ and total antioxidant reserve in tissue homogenates. HNE-His adducts, lipid peroxidation end products, were measured in lung homogenates by ELISA using the OxiSelect hydroxynonenal (HNE-His) adduct kit (Cell Biolabs Inc., San Diego, CA). The quantity of HNE-His adducts in protein samples were evaluated by comparing its absorbance with that of a known hydroxynonenal-bovine serum albumin (HNE-BSA) standard curve. The quantity of oxidatively modified proteins in lung homogenates, as assessed by measurement of protein carbonyls, was 
determined using the Biocell PC ELISA kit (Northwest Life Science Specialties). The amount of protein carbonyls was measured spectrophotometrically at $450 \mathrm{~nm}$. The level of vitamin $\mathrm{E}$ in lung homogenates was determined using VE Elisa kit (Biotang Inc., Lexington, MA) according to manufacturer's instructions. Extracts of vitamin E from lung homogenates were prepared using a procedure described by Lang and his co-workers [30], prior to the measurements. Total antioxidant capacity in lung homogenates was measured using NWLSS TAC-Peroxyl assay kit (Northwest, Vancouver, WA) according to the manufacturer's instructions. The degree of chemiluminescence quenching is proportional to the radical trapping ability of the antioxidant sample. The luminescence was recorded using a luminometer (Synery H1, Winooski, VT) at $1 \mathrm{~s}$ integration time for a $15 \mathrm{~min}$ period until the last maximal plateau was reached. The antioxidant concentration of samples was determined by comparing induction time to that of a known standard curve.

\section{Measurement of cytokines}

Cytokines in the BAL fluids from mice exposed to repeated $\mathrm{CNC}$ exposure were analyzed using a Bio-Plex system: 23-Plex cytokines/chemokines and TGF- $\beta$ 3-plex assays (Bio Rad, Hercules, CA). The concentrations were calculated using Bio-Plex Manager 6.1 software (Bio-Rad, Hercules, CA) based on standard curves.

\section{Lung collagen measurements}

Total lung collagen content was determined by quantifying total soluble collagen using the Sircol Collagen Assay kit (Accurate Chemical and Scientific Corporation, Westbury, NY). Briefly, lungs were homogenized in $0.7 \mathrm{ml}$ of $0.5 \mathrm{M}$ acetic acid containing pepsin (Accurate Chemical and Scientific Corporation, Westbury, NY) with 1:10 ratio of pepsin: tissue wet weight. Each sample was stirred vigorously for $24 \mathrm{~h}$ at $4{ }^{\circ} \mathrm{C}$, centrifuged, and $200 \mu \mathrm{l}$ of supernatant was assayed according to the manufacturer's instructions.

\section{Estrogen (E) level evaluation}

Level of the endogenic mouse estrogen (E) concentration in the serum of mice exposed to $\mathrm{CNC}$ was assessed using E Elisa kit (My BioSource, San Diego, CA) according to the manufacturer's instructions. This assay employs the competitive inhibition enzyme immunoassay technique. The estrogen concentration of samples was determined from a standard curve.

\section{Airway hyperresponsiveness evaluation}

The responsiveness of mouse airways was measured 3 month post-CNCexposure using a non-invasive wholebody plethysmograph (WBP) system (Buxco Systems Inc., Troy, NY). Briefly, mice were placed in WBP of approximately $300 \mathrm{~mL}$ in which the animals were unrestrained and exposed to increasing concentrations (10, $25,50 \mathrm{mg} / \mathrm{ml}$ ) of aerosolized methacholine (MCh; Sigma Aldrich, St. Louis, MO). After the baseline measurements, $\mathrm{MCh}$ is nebulized for $1.5 \mathrm{~min}$, and pressure changes within the chamber due to respiration were monitored and recorded (2 $\mathrm{min} /$ concentration). The pressure signals were post-processed using Matlab (Mathworks, Inc.) to calculate airway reactivity and expressed as enhanced pause (Penh) values. Penh is a reasonable analogue of airway responsiveness to a nonspecific inhaled stimulus, such as $\mathrm{MCh}$, which provides an accepted measure for comparison between the experimental groups.

\section{Total RNA extraction, microarray hybridization \& statistical analysis of microarray data}

Global gene expression for each treatment was determined using high-throughput mRNA microarray analysis following Minimum Information About a Microarray Experiment (MIAME) guidelines. Total RNA was isolated from left lung tissues of control and $\mathrm{CNC}$ exposed male and female mice 3 months post exposure $(n=5$ for each group). The RNA was isolated using TRIzol reagent (Invitrogen, Carlsbad, CA, USA) and purified using RNeasy MiniKits (Qiagen, Mississauga, ON, Canada) as described by the manufacturer. On-column DNase treatment was applied (Qiagen, Mississauga, ON, Canada). All RNA samples showing A260/280 ratios between 2.0 and 2.15 were further analyzed for RNA integrity using an Agilent 2100 Bioanalyzer (Agilent Technologies, Mississauga, ON, Canada). RNA integrity numbers above 5.0 were used in the experiment. Total RNA was stored at $-80{ }^{\circ} \mathrm{C}$ until microarray analysis. A total of $200 \mathrm{ng}$ of RNA from each sample ( 5 per treatment group) was analyzed by microarray hybridization on Agilent $8 \times 60 \mathrm{~K}$ oligonucleotide microarrays (Agilent Technologies Inc., Mississauga, ON, Canada). Data were acquired using Agilent Feature Extraction software version 9.5.3.1. A reference design [31-33] with the median signal intensities was used for the microarray data analysis. Five biological replicates per experimental condition and for each gender were considered for the analysis. The background for each array was measured using the (-)3xSLv1 probe. Spots with median signal intensities less than the trimmed mean (trim $=5 \%$ ) plus three trimmed standard deviations of the (-)3xSLv1 probe were flagged. All pre-processing of the data was conducted using $R$ [34]. The data was normalized using the global lowess method [35] using the transform.madata function in the MAANOVA library [36]. The background estimates as well as boxplots, cluster analysis and principle component analysis were used to identify microarrays with poor data quality and outliers. Differentially expressed genes 
were identified using the Fs statistic [37] in the MAANOVA library for each time point independently. The $p$-values were estimated using the permutation method (30,000 permutations with residual shuffling). The least-squares means $[38,39]$, a function of the model parameters was used to estimate the fold changes for each pairwise comparison. Genes showing expression changes of at least 1.2-fold in either direction compared to their matched controls and having p-values of less than or equal to $0.05(\mathrm{p} \leq 0.05)$ were considered significantly differentially expressed and were considered for further analysis. As most of the cytokine protein levels in the lungs were similar in trend to those observed in their corresponding mRNA levels in microarrays as well as consistent with their differences between males versus females (e.g., Eotaxin or CCL11, MIP-1 $\beta$, IL-6, IL-12p70, Collagens), validation of microarray data by RT-qPCR was not considered necessary as part of the current study.

\section{Gene Ontology (GO), pathway analysis and prediction of transcriptional factors}

The gene ontology (GO) and Kyoto Encyclopedia of Genes and Genomes (KEGG) pathway enrichments associated with differentially expressed genes was performed using Database for Annotation, Visualization and Integrated Discovery (DAVID) v6.7 software [40, 41]. To obtain an overview of perturbed functions in the lungs upon exposure to $\mathrm{CNC}$ in male and female mice, the Cellular Component, Biological Process and Molecular Function annotations were classified into broad groups based on the GO-slim classification system using CateGOrizer [42]. Further the CateGOrizer outputs were directly exported to Reduce Visualize Gene Ontology (REViGO) for a semantic representative subset analysis of non-redundant GO terms [43]. The prediction of the key transcriptional factors which regulated the expression of the upregulated differentially expressed genes (DEG)s in males and females upon exposure to CNC was performed using ChEA (ChIP Enrichment Analysis) software tool [44]. A $P$ value cutoff of $\leq 0.05$ was considered significant in each case.

\section{Statistical analysis}

Results were compared by One Way ANOVA using the all pairwise multiple comparison procedures (HolmSidak method). All results are presented as mean + SEM. $P$ values of less than 0.05 were considered to indicate statistical significance.

\section{Results}

\section{CNC characterization}

AFM imaging revealed the presence of nanoscale particles with an average length of $158 \pm 97 \mathrm{~nm}$ and average width of $54 \pm 17 \mathrm{~nm}$, based on 200 particle measurements
(Fig. 1a-b). DLS determined the hydrodynamic diameter to be $149.8 \pm 2.6 \mathrm{~nm}$, in good agreement with AFM findings. A similar fibril morphology was observed using SEM, albeit on a larger scale, possibly due to aggregation during the SEM sample preparation (Fig. 1c). The elemental analysis performed using EDX produced expected atomic percentages, with oxygen as the most abundant element, followed by carbon, sulfur, and sodium (Fig. 1d). The presence of sulfur can be attributed to the production process for the $\mathrm{CNC}$, whereby organosulfate groups are formed during the cellulose hydrolysis using sulfuric acid, and sodium-containing solutions may be utilized during the neutralization step. For clarity, elemental analysis ignored any observed silicon, as its presence was attributed to the use of a silicon wafer. Zeta potential of the nanocellulose material was determined to be $-68.26+/-2.89 \mathrm{mV}$. The negative surface charge of the nanocellulose is expected due to the presence of deprotonated organosulfate functionalities introduced during the manufacturing process.

\section{CNC induced pulmonary damage, inflammatory cell recruitment and cytokine responses}

Assessment of pulmonary damage following 3 months post $\mathrm{CNC}$ exposures administered by pharyngeal aspiration revealed that exposure to $\mathrm{CNC}$ caused substantial lung damage in both male and female mice with higher damage observed in female mice. In particular, level of LDH (67\% vs $21 \%$ ) and total protein content (31\% vs $13 \%)$ were increased significantly in female compared to male treated ones, respectively ( $p<0.05$; Fig. $2 \mathrm{a}, \mathrm{b}$ ).

Exposure to respirable $\mathrm{CNC}$ caused significant rise in total cell numbers and macrophages in BAL irrespective of the gender (Fig. 3a). However, CNC-exposed female mice showed a significantly higher fold increase in total PMN and lymphocytes compared to male mice (59 vs 34 ) and (31 vs 9), respectively (Fig. 3b). The increase in the activity of MPO, an abundant leukocyte protein that generates reactive oxidants, was greater in the female lungs compared to that observed in male mice (Fig. 3c). Multi-nucleated giant cells (MGCs), merged monocytes and/or macrophages [45] reflective of chronic inflammation were found in BAL fluid of mice after 3 months following $\mathrm{CNC}$ exposure (Fig.4a-c). The number of MGCs found in BAL cells recovered from females was 2.8 fold higher compared to that observed in males (Fig. 4d). Several pro-inflammatory cytokines were increased following exposure to $\mathrm{CNC}$, likely contributing to the development and/or progression of CNC-induced lung inflammation. Panel of inflammatory, adhesive molecules and immunogenic mediators are listed in Table 1. Following 3 months post exposure to $\mathrm{CNC}$, the foldincrease of the levels of IL-1 $\beta$, IL-10, IL-12p70, KC, MCP-1, MIP- $1 \alpha$ and MIP-1 $\beta$ were significantly greater 


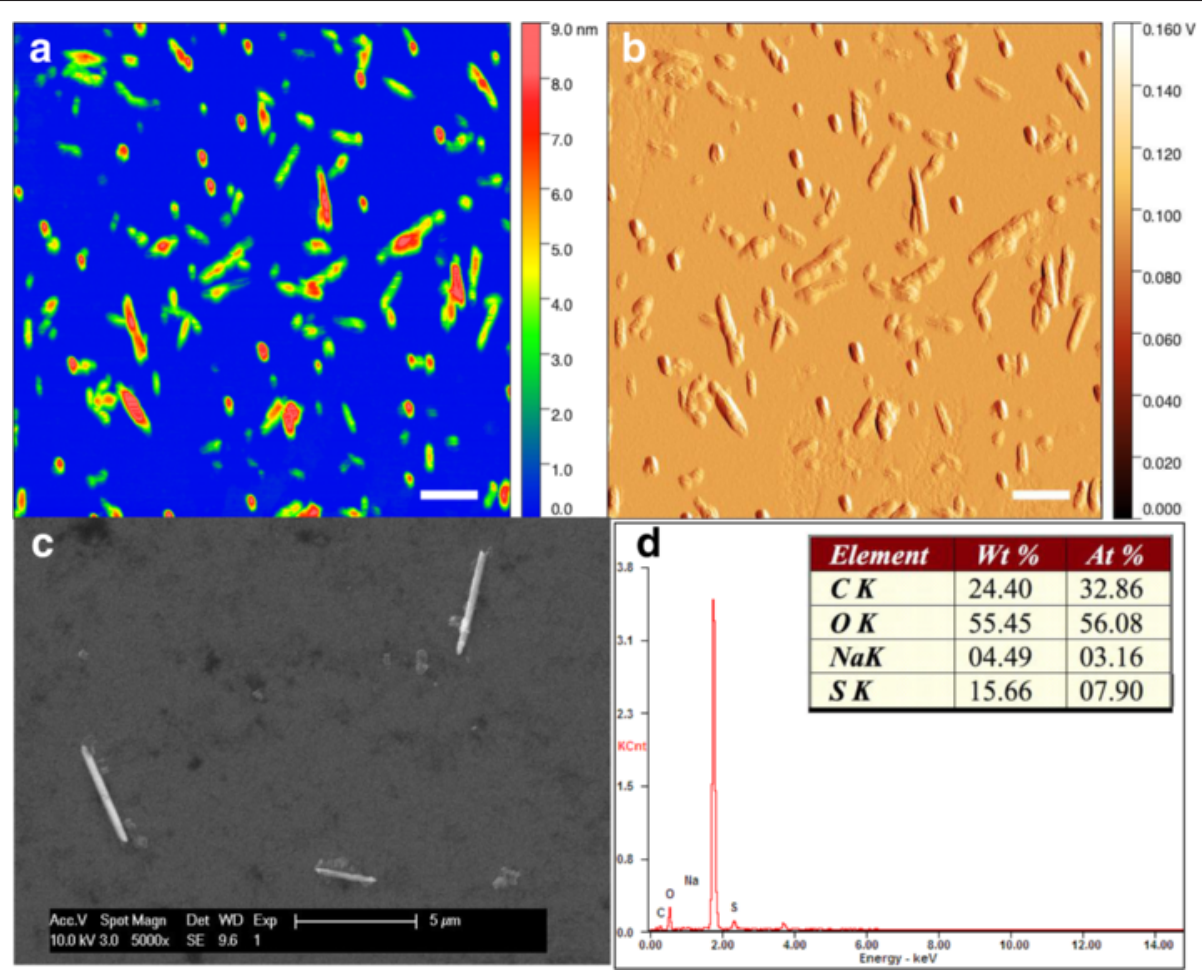

Fig. 1 Imaging of CNC using AFM height (a) and amplitude (b) modes, and SEM (c). The EDX spectrum is also shown (d), along with the calculated weight percentages ( $\mathrm{Wt} \%$ ) and atomic percentages (At\%). Silicon elemental contributions are ignored in the EDX analysis. Scale bars are $200 \mathrm{~nm}$ for $\mathbf{a}$ and $\mathbf{b}$

in BAL fluids of females compared to male mice. Other cytokines including IL-1 $\alpha$, IL-2, IL-4, IL-2p40, G-CSF and RANTES were increased in BAL fluids of both genders (Table 1). While the expression of Eotaxin was only found in $\mathrm{CNC}$ exposed male mice, the increase in the levels of cytokines IL-5, IL-6, Il-12p70,
IL-13 and IL-17A were unique to CNC exposed female mice (Fig. 5).

\section{CNC induced oxidative stress}

Several markers of oxidative stress including total antioxidant reserve, level of carbonyls, fat soluble antioxidant,
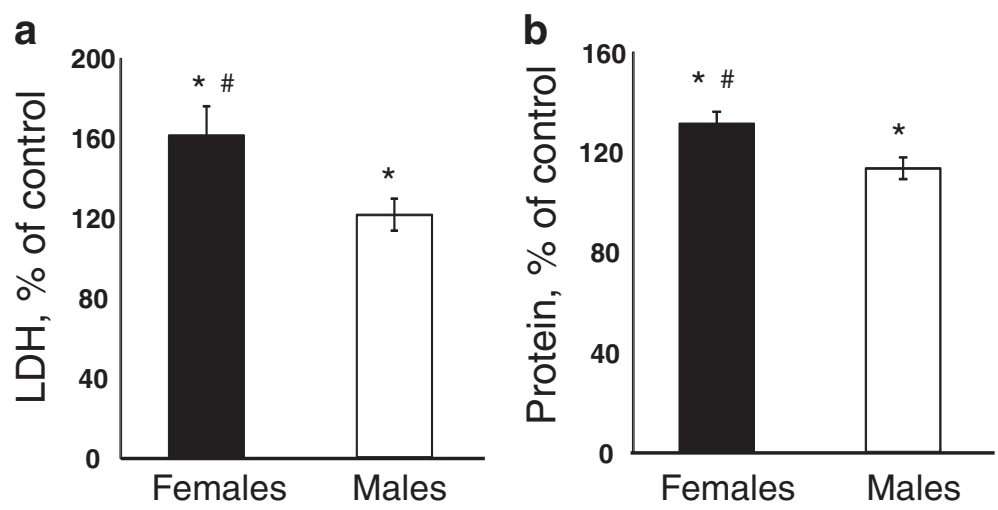

Fig. 2 Pulmonary tissue damage measured as LDH (a) and Protein (b) in BAL of C57BL/6 mice 3 months after repeated exposure to CNC (cumulative dose of $240 \mu \mathrm{g} /$ mouse). Black columns - female mice exposed to CNC, open columns - male mice exposed to CNC. Mean absolute values of $\mathrm{LDH}$ in BAL from PBS-exposed control male and female mice were $53.8 \pm 2.9 \mathrm{U} / \mathrm{L}$ and $52.3 \pm 2.1 \mathrm{U} / \mathrm{L}$, respectively. Mean absolute values of protein level in BAL from PBS-exposed control male and female mice were $0.238 \pm 0.005 \mathrm{mg} / \mathrm{ml}$ and $0.224 \pm 0.009 \mathrm{mg} / \mathrm{ml}$, respectively. No significant differences were found between levels of $L D H$ and protein measured in the BAL of controls from male and female mice. Mean \pm SEM ( $n=10$ mice/group). ${ }^{*} p<0.05$, vs control PBS-exposed mice, ${ }^{\#} p<0.05$, vs male mice exposed to CNC 

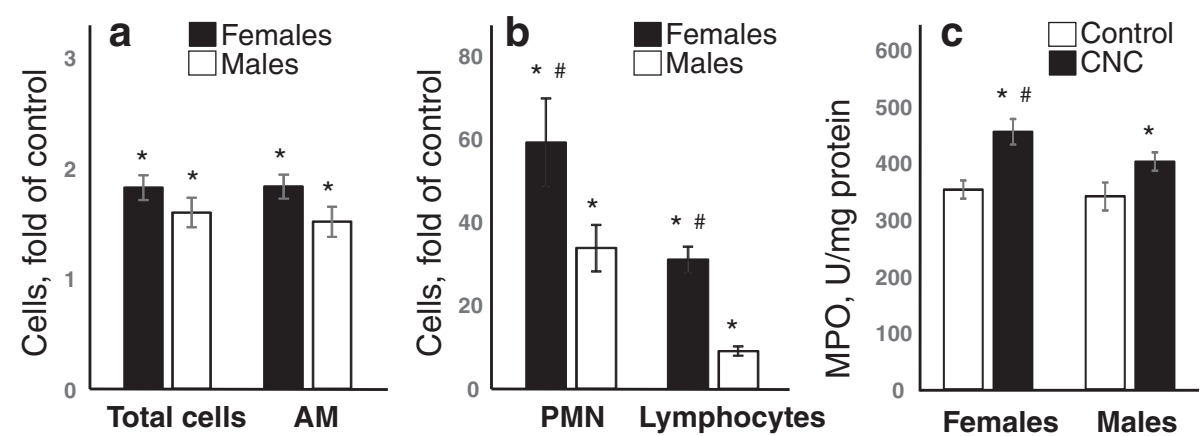

Fig. 3 Pulmonary inflammation evaluated by assessment of $(\mathbf{a}, \mathbf{b})$ cell profile from BAL of mice and (c) activity of myeloperoxidase (MPO) in lung homogenates of C57BL/6 mice 3 months after repeated pharyngeal aspiration with CNC (cumulative dose of $240 \mu \mathrm{g} / \mathrm{mouse}$ ). $\mathbf{a}$, $\mathbf{b}$ Black columns - female mice exposed to CNC, open columns - male mice exposed to CNC. Mean absolute values from PBS-exposed control female mice were $(394.4 \pm 28.6) \times 10^{3},(373.8 \pm 26.5) \times 10^{3}, 430.0 \pm 214.0$, and $396.0 \pm 199.0$ for total cells, alveolar macrophages, PMNs and lymphocytes, respectively. Mean absolute values from PBS-exposed control male mice were $(343.6 \pm 40.7) \times 10^{3},(341.3 \pm 40.2) \times 10^{3}, 645.3 \pm 204.0$, and $899.4 \pm 218.0$ for total cells, alveolar macrophages, PMNs and lymphocytes, respectively. No significant differences were found between number of total cells, alveolar macrophages, PMNs and lymphocytes in controls from female and male mice. Mean \pm SEM ( $n=10$ mice/group). ${ }^{*} p<0.05$, vs control PBS-exposed mice, ${ }^{*} p<0.05$, vs male mice exposed to CNC. c Open columns - control mice, black columns -mice exposed to CNC. No significant differences were found between levels of MPO measured in the lung homogenates from females and males control mice. Mean \pm SEM ( $n=10$ mice/ group). ${ }^{*} p<0.05$, vs control PBS-exposed mice, ${ }^{\#} p<0.05$, vs male mice exposed to CNC
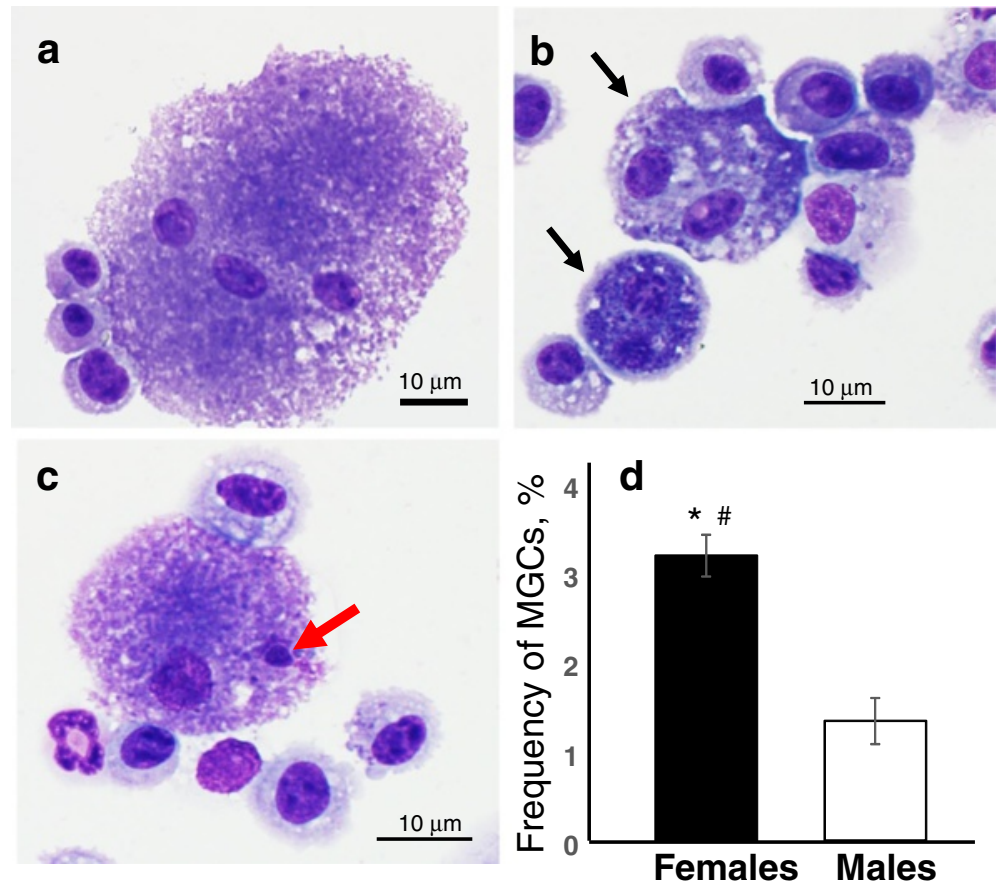

Fig. 4 Representative light micrographs of giant multi-nucleated (a-c) cells including bi-nucleated (b) and micro-nucleated (c) alveolar microphages from BAL fluids of female mice 3 month post repeated exposure with CNC (marked by arrows). Frequency of giant multi-nucleated cells (MGCs) in BAL fluids of female or male mice 3 month after the last exposure with CNC (d). Black columns - giant BAL cells from female mice exposed to CNC, open columns- giant BAL cells from male mice exposed to CNC. Mean \pm SEM ( $n=10$ mice/group). ${ }^{*} p<0.05$, vs control PBS-exposed mice, ${ }^{\#} p<0.05$, vs male mice exposed to CNC. Blind-coded slides were independently scored by two readers. A total of 2000 cells per sample were scored. No MGCs were found in control mice 
Table 1 Comparison of the levels of inflammatory cytokines and chemokines in the BAL fluid of C57BL/6 female and male mice 3 months after repeated exposure with CNC

\begin{tabular}{|c|c|c|c|}
\hline Cytokines & Control $(\mathrm{pg} / \mathrm{ml})$ & Females (fold of control) & Males (fold of control) \\
\hline IL-1a & $1.11 \pm 0.05$ & $1.78 \pm 0.08^{*}$ & $1.87 \pm 0.10^{*}$ \\
\hline$I L-1 \beta$ & $24.75 \pm 0.70$ & $2.21 \pm 0.12^{* \#}$ & $1.68 \pm 0.08^{*}$ \\
\hline $\mathrm{IL}-2$ & $1.95 \pm 0.11$ & $1.73 \pm 0.12^{*}$ & $1.69 \pm 0.19^{*}$ \\
\hline $\mid \mathrm{L}-4$ & $2.68 \pm 0.03$ & $1.34 \pm 0.04^{*}$ & $1.29 \pm 0.02^{*}$ \\
\hline $\mid \mathrm{L}-5$ & $1.77 \pm 0.10$ & $1.87 \pm 0.11^{* \#}$ & $0.85 \pm 0.09$ \\
\hline IL-6 & $3.92 \pm 0.17$ & $1.29 \pm 0.08^{*}$ & $1.08 \pm 0.05$ \\
\hline IL-10 & $6.83 \pm 0.27$ & $1.53 \pm 0.08^{* \#}$ & $1.28 \pm 0.12^{*}$ \\
\hline \multirow[t]{2}{*}{ IL-12(p40) } & $110.30 \pm 7.11^{a}$ & $3.80 \pm 0.26^{*}$ & $3.20 \pm 0.27^{*}$ \\
\hline & $66.76 \pm 1.99^{\beta}$ & & \\
\hline IL-12(p70) & $24.95 \pm 0.80$ & $1.36 \pm 0.07^{* \#}$ & $1.17 \pm 0.04$ \\
\hline $\mid \mathrm{L}-13$ & $113.39 \pm 3.09$ & $1.27 \pm 0.04^{*}$ & $1.16 \pm 0.05$ \\
\hline IL-17A & $4.20 \pm 0.20$ & $1.51 \pm 0.06^{* \#}$ & $0.99 \pm 0.08$ \\
\hline Eotaxin & $468.96 \pm 32.56$ & $1.15 \pm 0.07$ & $1.32 \pm 0.07^{*}$ \\
\hline G-CSF & $6.77 \pm 0.19$ & $1.32 \pm 0.05^{*}$ & $1.18 \pm 0.08^{*}$ \\
\hline KC & $7.73 \pm 0.21$ & $4.16 \pm 0.56^{* \#}$ & $2.33 \pm 0.18^{*}$ \\
\hline MCP-1 & $29.30 \pm 0.72$ & $8.15 \pm 1.7^{* \#}$ & $2.35 \pm 0.26^{*}$ \\
\hline MIP-1a & $5.81 \pm 0.16$ & $13.43 \pm 1.63^{* \#}$ & $6.51 \pm 0.64^{*}$ \\
\hline MIP-1 $\beta$ & $3.50 \pm 0.18$ & $2.17 \pm 0.12^{* \#}$ & $1.42 \pm 0.09^{*}$ \\
\hline RANTES & $2.37 \pm 0.22$ & $1.87 \pm 0.15^{*}$ & $1.90 \pm 0.28^{*}$ \\
\hline
\end{tabular}

The control values otherwise noted correspond to the mean absolute values $(\mathrm{pg} / \mathrm{ml})$ from PBS-exposed male mice. The PBS-exposed control female and male mice were not significantly different, except for IL-12(p40). Level of IL-12(p40) for control females ${ }^{\alpha}$ mice $(110.30 \pm 7.11 \mathrm{pg} / \mathrm{ml})$ was significantly different as compared to control males ${ }^{\beta}$ mice $(66.76 \pm 1.99 \mathrm{pg} / \mathrm{ml})$. For comparison, cytokines data presented as folds of control for female and male mice exposed to CNC. Mean \pm SEM ( $n=10$ mice/group). ${ }^{*} p<0.05$, vs control PBS-exposed mice, ${ }^{\#} p<0.05$, vs male mice exposed to CNC

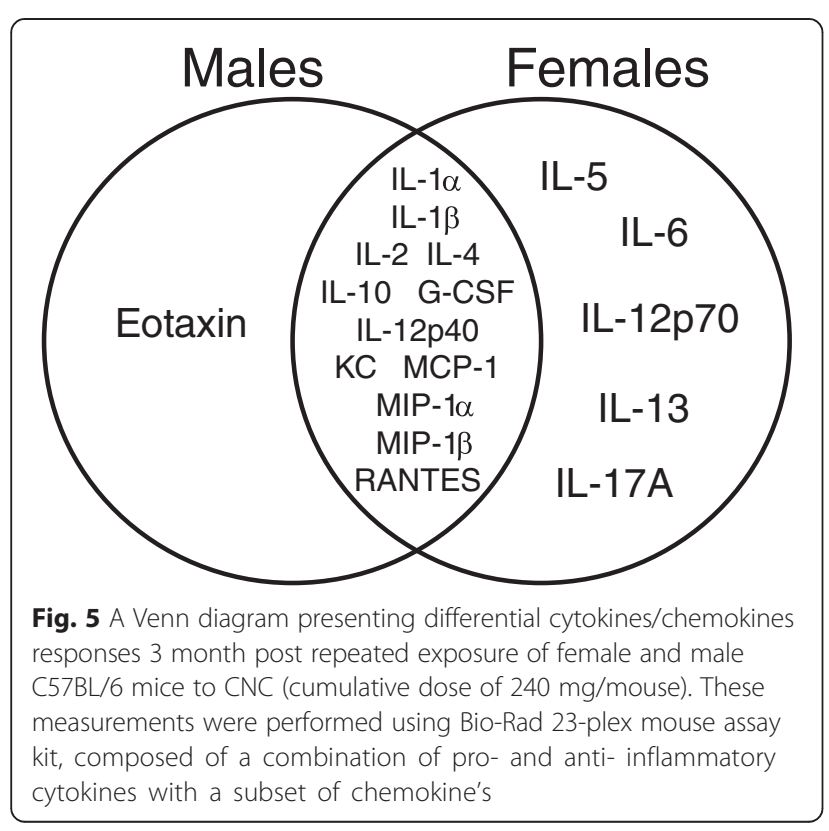

vitamin E, and lipid peroxidation products, 4hydroxynonenal (HNE), were measured in the lungs of female and male mice following 3 months post repeated CNC exposure (Fig. 6). Total antioxidant reserve was 2.8fold lower after $\mathrm{CNC}$ exposure in female mice compared to 1.4-fold lower levels seen in males (Fig. 6a). Level of vitamin $\mathrm{E}$ in female mice was decreased 2.2-fold compared to 1.4-fold in males (Fig. 6b). CNC caused a 1.4-fold accumulation of protein carbonyls in female mice, while no significant changes were found in the lungs of male mice (Fig. 6c). 4-HNE, a common byproduct of lipid peroxidation was increased in females and males 1.2 and 1.1 fold, respectively $(p<0.05$; Fig. $6 \mathrm{~d})$.

\section{CNC facilitated increase of TGF- $\beta 1$ and collagen accumulation}

TGF- $\beta 1$ is a pleiotropic cytokine secreted by a number of immune cells including macrophages. We found that elevation of TGF- $\beta 1$ was significantly greater in BAL fluids of females compared to that found in male mice. In particular, level of TGF- $\beta 1$ in female mice was 3.2 fold higher compared to that seen in males (Fig. 7a). Collagen increase in mouse lungs was also significantly greater in females compared to males (Fig. 7b). 

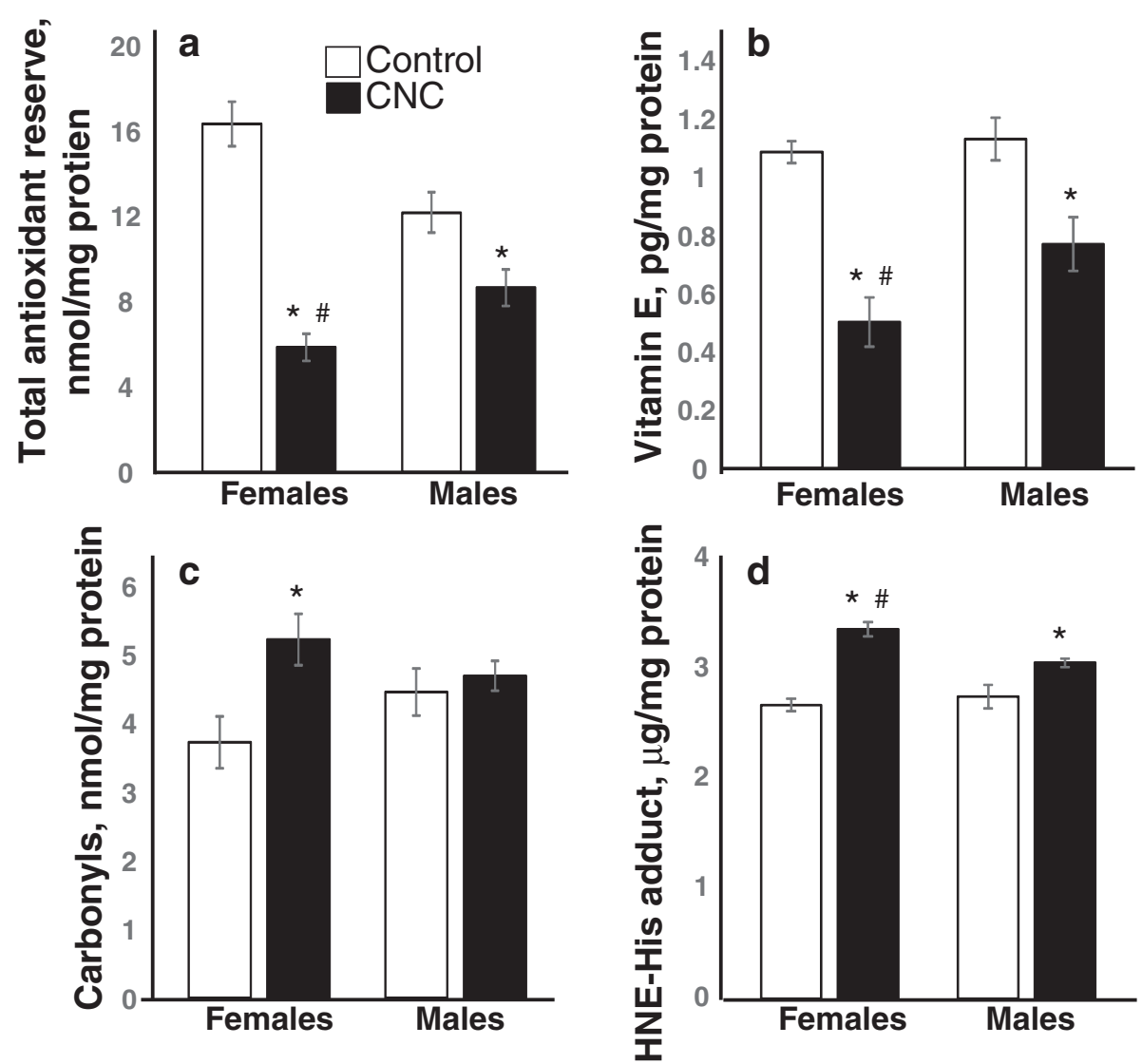

Fig. 6 Oxidative stress evaluated by measurements of a total antioxidant reserve, $\mathbf{b}$ vitamin E, c protein carbonyls and $\mathbf{d}$ HNE-His adduct in the lung homogenates of C57BL/6 mice 3 months after repeated exposure to CNC. Open columns - control mice, black columns - mice exposed to CNC. Mean \pm SEM ( $n=5-10$ mice/group). ${ }^{*} p<0.05$, vs control PBS-exposed mice, ${ }^{\#} p<0.05$, vs male mice exposed to CNC
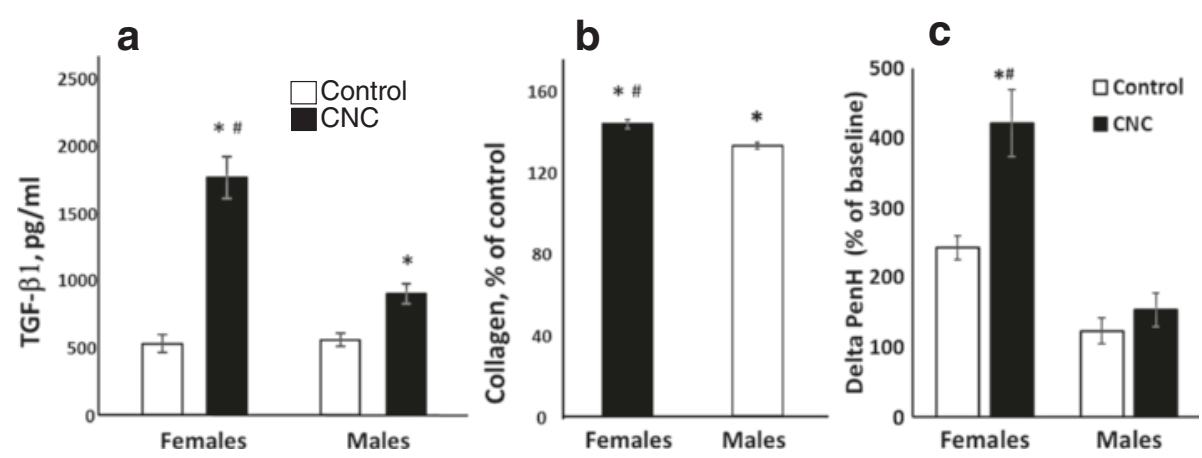

Fig. 7 Levels of TGF- $\beta 1$ in the BAL (a), levels of collagen (b) and airway reactivity to direct stimulation of MCh (c) measured in the lung of female and male C57BL/6 mice 3 month post repeated exposure to CNC (cumulative dose of $240 \mathrm{\mu g} / \mathrm{mouse}$ ). a \& c Open columns - control mice, black columns - mice exposed to CNC. Mean \pm SEM ( $n \geq 5$ mice/group). ${ }^{*} p<0.05$, vs control PBS-exposed mice, ${ }^{\#} p<0.05$, vs male mice exposed to CNC. $\mathbf{b}$ Black columns - female mice exposed to CNC, open columns - male mice exposed to CNC. Mean absolute values of collagen in the lung of PBS-exposed control male and female mice were not significantly different $(36.02 \pm 1.90 \mu \mathrm{g} / \mathrm{mg}$ lung and $32.20 \pm 1.50 \mu \mathrm{g} / \mathrm{mg}$ lung, respectively). Mean $\pm \operatorname{SEM}\left(n=10\right.$ mice/group). ${ }^{*} p<0.05$, vs control PBS-exposed mice, ${ }^{\#} p<0.05$, vs male mice exposed to CNC 


\section{Airway responsiveness to direct stimulation of MCh}

Airway reactivity in responses to direct stimulation of MCh challenge is depicted in Fig. 7c. Data are shown as percent delta Penh, representing the difference between the maximum value registered post-MCh challenge at $50 \mathrm{mg} / \mathrm{ml}$ concentration and the baseline Penh in each case. Although modest increases in Penh after MCh challenge were also observed in controls, the magnitude of the response was significantly altered in $\mathrm{CNC}$ exposed mice. Most importantly exposure to $\mathrm{CNC}$ significantly $(p<0.05)$ increased airway responsiveness to $\mathrm{MCh}$ as compared to control (PBS) mice by $\sim 1.7$-fold only in females (Fig. 7c). No significant change in airway reactivity was observed at $50 \mathrm{mg} / \mathrm{ml}$ concentration of $\mathrm{MCh}$ in male mice compared to their respective controls. Interestingly the overall airway reactivity responses to direct stimulation of $\mathrm{MCh}$ challenge were elevated in both female control mice as well as $\mathrm{CNC}$ exposed mice, compared to males (Fig. 7c).

\section{Histopathology}

Microscopic sections of the lungs in the control animal groups (both males and females) reveal normal histology of conductive and respiratory airways. Three months post repeated $\mathrm{CNC}$ exposure microscopic sections of male and female lungs reveal chronic peribronchial and perivascular inflammation (Fig. 8), and numerous alveolar macrophages, including multi-nucleated forms (Fig. 9). The degree of perivascular inflammation was higher in females than in males.

\section{Differentially expressed genes in males versus females upon exposure to CNC}

Global pulmonary gene expression changes were assessed in the lung tissue of males and females 3 months post exposure to CNC. A total of 845 and 794 of the 22,486 probes were significantly differentially expressed $(\geq 1.2$ folds, $\mathrm{p} \leq 0.05)$ in male and female mice, respectively (Additional file 1: File S1). Figure 10 shows the overlap of DEGs across both genders. A total of 68 genes were found to be commonly regulated in the lungs upon exposure to $\mathrm{CNC}$ in males $(\sim 8.0 \%)$ and females $(\sim 8.5 \%)$. A small overlap in the DEGs between males and females suggests that pulmonary outcomes and toxicity associated with $\mathrm{CNC}$ exposures could be gender dependent.

\section{Analysis of GO terms associated with DEGs of CNC exposure in males versus female mice}

A detailed GO enrichment analysis of every biological process (BP), molecular function (MF) and cellular component (CC) associated with DEGs upon exposure to $\mathrm{CNC}$ in male and female mice was conducted using DAVID [40, 41]. A significant number of GO terms in each category were found to be commonly enriched upon $\mathrm{CNC}$ exposure in both males and females (Additional file 2: Table S1 and Additional file 3: File S2). The enriched GO-terms commonly found in both males and females (Additional file 2: Table S1) generally included housekeeping genes, including those for cellular organization and biogenesis (GO:0016043), metabolism (GO:0008152) and development (GO:0007275) processes, response to stress/stimuli (GO:0006950, GO:0009605), cell communication (GO:0007154) and signal transduction (GO:0007165). The analysis of non-redundant GO-terms using ReVIGO [43], indicated the enrichment of MFs related to nuclease activity, ion- and chemokine binding, lipoxygenase- and receptor activity in females; and enrichment of nucleotide/cytokine binding, hydrolase-/ oxidoreductase-/cytokine receptor-/enzyme inhibitor activity functions in males (Fig. 11). In particular, enriched categories under MF and CC together implicated the abundance of intracellular/cytoplasmic genes
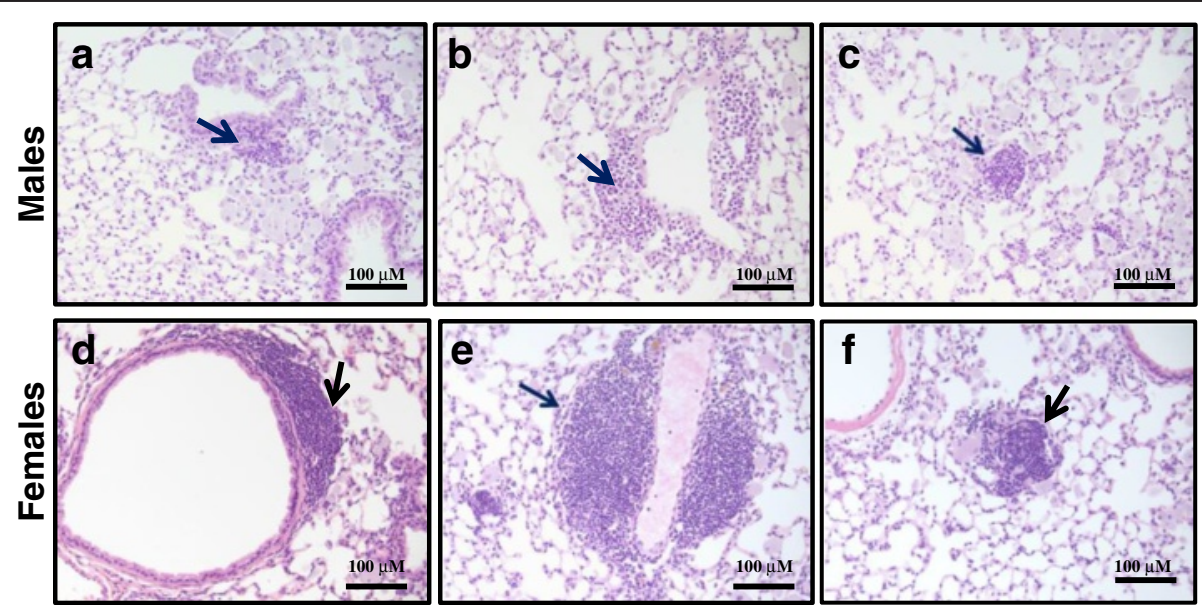

Fig. 8 Light micrographs of H\&E stained sections from lungs of female and male C57BL/6 mice 3 month post CNC repeated exposure showing chronic pulmonary inflammation: peribronchial ( $(\mathbf{a} \& \mathbf{d})$, perivascular $(\mathbf{b} \& \mathbf{e})$ and parenchymal $(\mathbf{c} \& \mathbf{f})$ 

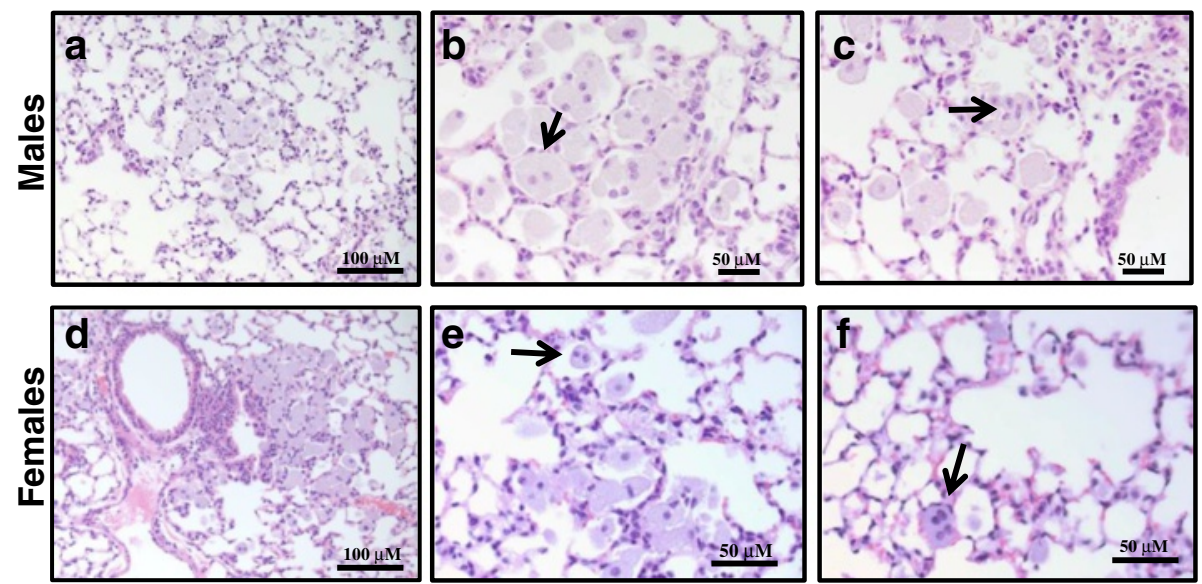

Fig. 9 Light micrographs of H\&E stained sections from lungs of female and male C57BL/6 mice 3 month post CNC repeated exposure showing giant alveolar macrophages ( $\mathbf{a} \& \mathbf{d})$, bi- (b \& e) and multi- nucleated (c \& $\mathbf{f}$ ) cells

and their crucial role in biological processes focused on cellular development/function/growth and response to stimuli in males (Additional file 2: Table S1 and Fig. 11A). Similarly in females, the abundance of genes localized in extracellular and plasma membrane regions reflects their overrepresentation in carrying out biological functions related to cell adhesion, cellular metabolism/catabolism and inflammation (Additional file 2: Table S1 and Fig. 11B). Interestingly, the involvement of many DEGs in carbohydrate/pattern/polysaccharide and glycosaminoglycan binding were found to be commonly enriched between both males and females. This suggests that irrespective of gender (Fig. 11), one can specifically detect changes in gene expression profiles that are reminiscent of effects in response to other small molecules similar to cellulose nanomaterials such as chitin, amino glycan's, poly saccharides etc.

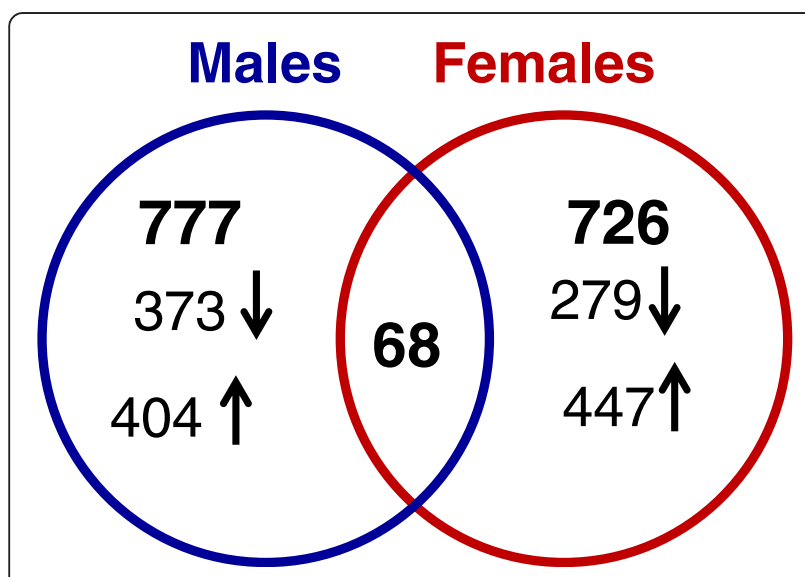

Fig. 10 Overlap of differentially expressed genes from both genders of C57BL/6 mice 3 months after repeated exposure to CNC
KEGG pathway enrichment analysis

The KEGG pathway enrichment analysis was performed for both up- and downregulated DEGs in males and females 3 months post exposure to CNC particles. While both up- and down-regulated DEGs in males were commonly found to be mostly enriched in circadian rhythm signaling, the KEGG pathways involved in metabolism (e.g, fructose and mannose, drug, retinol) and calcium signaling were only significantly enriched by upregulated DEGs; and pathways related to cancer (e.g., bladder, prostate) and inflammatory response (e.g., cytokinecytokine receptor interaction, chemokine signaling, phagocytosis, leukocyte transendothelial migration, antigen presentation and processing) were significantly enriched by downregulated DEGs (Additional file 4: Table S2). In females, upregulated genes were mostly enriched in inflammatory and immune response signaling (e.g., chemokine signaling, cytokine-cytokine receptor interactions, endocytosis), while downregulated genes were significantly enriched in gap junction, melanogenesis, axon guidance, calcium and chemokine signaling pathway (Additional file 4: Table S2). Further analysis of the enriched KEGG pathways suggested specific differences in the responses of males and females. While the cytokine-cytokine receptor interaction and chemokine signaling pathways were significantly enriched by upregulated genes in females, in males they were significantly enriched by downregulated DEGs. These results clearly highlight gender specific differential regulation of pathways and signaling mechanisms related to inflammatory responses upon exposure to $\mathrm{CNC}$ materials.

\section{Significant transcriptional factors for upregulated DEGs} Considering that most changes in gene expression are controlled by upstream regulatory transcriptional factors, 


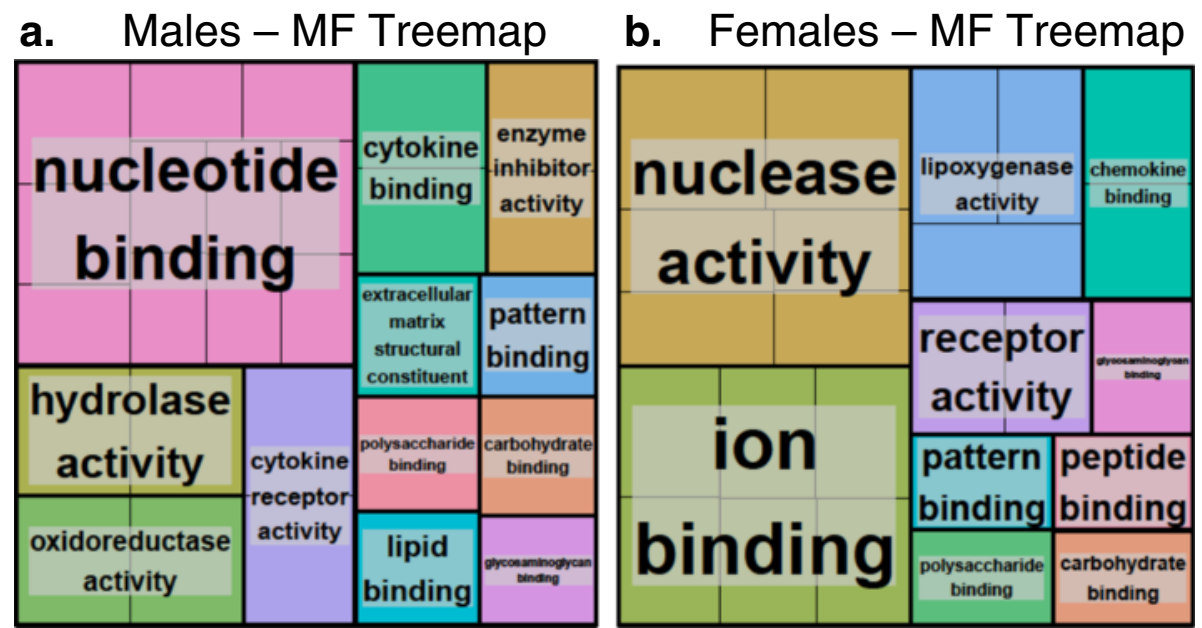

Fig. 11 The enrichment of differentially expressed genes among molecular function category in mice exposed to CNC. Treemaps of DEGs in a males and $\mathbf{b}$ females generated using REVIGO. Each rectangle is a single cluster representative. The representatives are joined into 'superclusters' of loosely related terms, visualized with different colors. Size of the rectangles reflects either the $p$-value, or the frequency of the $G O$ term in a given cluster. For more details please refer to methods section

we searched on ChEA for transcriptional factors that could regulate the upregulated genes identified both in males and females. A total of 70 transcriptional factors in males and 74 in females were predicted to significantly $(p<0.005)$ modulate upregulated DEGs in each case (Additional file 5: File S3). Most importantly, the regulation of transcription factors related to oxidative stress mechanism and antioxidant responses (e.g., NRF2, ESR1, SOX2, NR1I2, KLF2/4/5) were most significant in males, the regulation of factors related to cell cycle/death and differentiation (e.g., KDM5B, TAL1, TRIM28, CREM, SMARCA4) as well as immune/inflammatory responses (e.g., CEBPB, CREB1) were significant in females. Disregarding the overlapping transcriptional factors between males and females, the regulators of cell cycle/death/ differentiation including hematopoiesis (e.g., ZFP42, SFPI1, GATA1, FLI1, CCND1, RUNX1, LMO2) in females; and oxidative-stress mediated antioxidant responses (e.g., ESR1, NR1I2, TET1, BMI1) responses in males, were overrepresented by the upregulated DEGs (Additional file 5: File S3). Overall the transcription regulator analysis highlights significant enrichment of factors related to antioxidant mechanisms triggered in response to oxidative stress in males upon exposure to $\mathrm{CNC}$, and not females.

\section{Inflammatory and oxidative stress responses}

Inflammatory and antioxidant responses were among the most perturbed processes in the lungs upon exposure to $\mathrm{CNC}$ in females and males, respectively. Specifically, the inflammatory responses in females were in part driven by several cytokines/chemokines, including CXCL1, CCL3 and CCL4; and inflammatory genes such as PKCB, TNFSR4, CXCR6, LIF, IL2RB, ITK and ARRB.
A significant upregulation of genes corresponding to negative acute phase response (APR) including APOA2, AHSG and ALB was observed in the lungs of male mice (Additional file 1: File S1). However, no differential regulation of these negative APR genes were found in females, further supporting the enrichment of immune/inflammatory BP and MF GO categories in females than males. Decreased inflammation in males - compared to females is also corroborated by the upregulation of several antioxidant enzymes. A significant upregulation of genes related to phase I and II antioxidant/detoxification enzymes including CYP2E1, GSTA5, NQO1, EPHX (XDH) as well as antioxidant protein superoxide dismutase (SOD) was found only in the lungs of male mice. Thus, a trend for lack of antioxidant enzymes and/or proteins in females may contribute to the greater oxidative damage that could be a cause or consequence of inflammation.

\section{Discussion}

The high scale production of $\mathrm{CNC}$ and their growing applications in composite materials, electronics, food containers and appliances has gained increasing attention due to their high strength and stiffness combined with low weight, biodegradability and sustainability. While $\mathrm{CNC}$ hold great commercial potential, data regarding their health effects and safety are missing. The lungs are the primary route for particulates entrance into the human body. Several studies have reported pathological manifestation showing epithelial hyperplasia, granulomatous lesions, and fibrosis in rodent lungs following exposure to cellulose fibers [7, 9, 46-48]. Recent evidence also suggests that occupational exposure to $\mathrm{CNC}$, nanosized cellulose particles, could prime adverse pulmonary 
effects. The airborne $\mathrm{CNC}$ could be released during production and/or handling at the workplace [49, 50]. Bio-persistence of cellulose fibers shown in rat lungs could aggravate respiratory outcomes causing airway ailments [51-54]. The morphology, high aspect ratio and small aerodynamic diameter of $\mathrm{CNC}$ makes it possible to be effectively deposited in the gas exchange alveolar area. A recently published study demonstrated that $\mathrm{CNC}$ is highly biodurable and could be biopersistent [55]. Previously, we found that bolus administration of respirable $\mathrm{CNC}$ to mice elicited dose-dependent oxidative stress, tissue damage, and robust inflammatory responses in the lungs. In this study, we investigate the pulmonary outcomes induced by repeated CNC cumulative exposure to $240 \mu \mathrm{g}$ /mouse. We found that $\mathrm{CNC}$ caused impaired lung functions, pulmonary inflammation and damage. Accelerated oxidative stress, elevated TGF- $\beta$, and collagen deposition were observed in the lungs of $\mathrm{CNC}$ exposed mice. Interestingly, all these changes were highly expressed in female compared to male mice, clearly highlighting gender based differences in pulmonary responses upon exposure to CNC. To the best of our knowledge, the current study is the first to report or point out these pulmonary differences in male and female mice upon exposure to $\mathrm{CNC}$ materials.

The current Occupational Safety and Health Administration (OSHA) permissible exposure limit (PEL) set for cellulose is $15 \mathrm{mg} / \mathrm{m}^{3}$ (total dust) and $5 \mathrm{mg} / \mathrm{m}^{3}$ (respirable fraction) as $8 \mathrm{~h}$ time weighted average (TWA) concentration (29 CFR [56] 1910.1000, Table Z-1). Thus, under manufacturing settings, lung burdens comparable to those used in this study (adjusted by lung surface area) can be achieved by workers in 42 working days $\left(5 \mathrm{mg} / \mathrm{m}^{3}\right.$, lung ventilation of $9.6 \mathrm{~m}^{3} /$ day [27] and deposited pulmonary fraction of $20 \%$ [57]). Moreover, the doses of CNC utilized in the current study ( $240 \mu \mathrm{g} /$ mouse $)$ are relevant to the actual workplace and are certainly less than those that could be achieved during lifetime work exposures $(8 \mathrm{~h} / \mathrm{d}$, $5 \mathrm{~d} / \mathrm{wk}, 45$ yr, 29 CFR [56]) [58].

Previous studies have reported gender based differences in the expression of pro-inflammatory cytokines [59-62]. Cellular responses to airborne particulates are orchestrated by release/production of a number of inflammatory mediators. We found that the majority of cytokines/chemokines including IL- $1 \alpha$, IL-1 $\beta$, IL-2, IL-4, KC, MCP-1, MIP-1 $\alpha$, MIP-1 $\beta$, G-CSF, IL-10, IL-12p40, and RANTES were up-regulated in both genders upon exposure to CNC (Table 1). Increased release of cytokines/chemokines is also consistent with the recruitment of phagocytes, e.g., monocytes/macrophages neutrophils, and lymphocytes (Fig. 5). While Eotaxin was found to be uniquely expressed in the lungs of $\mathrm{CNC}$ exposed male mice, the up-regulation of IL-5, IL-6, IL-13, IL-12p70, and IL-17A was observed only in females (Table 1, Fig. 5). Notably, IL-17 family cytokines, IL-17A and IL-
$17 \mathrm{~F}$, that target innate immune cells and epithelial cells to produce G-CSF and IL-8 (CXCL8), are known to induce increased neutrophil production and recruitment. Recently, IL-17 has been shown to be associated with the development of lung inflammatory diseases such as chronic obstructive pulmonary disease (COPD). IL-17A is essential to the development of elastase-induced neutrophilic inflammation and lung emphysema, which was associated with increased levels of neutrophil-related chemokines such as KC, MIP-2 and IL-1 $\beta$ [63]. Recently, it has also been reported that overexpression of IL-17A induces mucus metaplasia via IL-13 [64]. Moreover, repeated exposure to $\mathrm{CNC}$ caused development of chronic peribronchial and perivascular pulmonary inflammation with deposition of numerous bi-nucleated and multinucleated alveolar macrophages in the lungs of both genders (Figs. 8 and 9). However, the degree of perivascular inflammation was higher in females. Compared to males, female mice clearly indicated an increased inflammatory response upon exposure to $\mathrm{CNC}$ materials. This is further supported by the GO enrichment, KEGG pathway (Additional file 4: Table S2) and upstream transcription factor regulator analysis based on significantly overexpressed genes in females (Additional file 5: File S3). In females, the enrichment of GO MF categories (e.g., cytokine binding, cytokine-receptor activity, inflammation), KEGG pathways (e.g., chemokine signaling, cytokinecytokine receptor interactions, endocytosis) and/or the prediction of regulatory factors (e.g., CEBPB, CREB1) involved in inflammatory and immune responses was apparent. Because oxidative stress can be the cause or consequence of inflammation, the contribution of gender difference in pro-inflammatory cytokines to gender difference in oxidative damage upon $\mathrm{CNC}$ exposure warrants further investigation.

$\mathrm{CNC}$ exposure also caused chronic pulmonary inflammation with manifested accumulation of MGCs in the lungs (Figs. 4 and 9). MGCs have been regarded as hallmark of chronic inflammation. Accumulation of MGCs have reported to play a role in hard metal lung disease leading to interstitial pneumonia and centrilobular fibrosis [65]. MGCs are also important mediators of tissue remodeling and repair and are also responsible for removal or sequestration of foreign material, intracellular bacteria and non-phagocytosable pathogens [66]. It has been reported previously that macrophage fusion factors (e.g., IL-4, IL13 and $\alpha$-tocopherol) and identified adhesion receptors and signaling intermediates, as well as an adhesion protein substrate (vitronectin) supported macrophage fusion forming MGC [45]. Studies on the molecular mechanism of macrophage fusion have revealed it to be a mannose receptor mediated phagocytic process $[45,67,68]$. In particular, IL-4 and IL-13, the two potent macrophage fusion factors, have been reported to up-regulate the expression 
of the mannose receptor that is essential for macrophage fusion $[65,66]$. Moreover, the effects of IL-13 and IL-4 were neither additive nor synergistic, and the maximum fusion was observed when both IL-4 and IL-13 were present. This is in line with the current study where overexpression of both IL-4 and IL-13 in females lead to increased MGCs compared to males that only had overexpression of IL-4 (Fig. 5). Further, the GO enrichment of "pattern/polysaccharide/glycosaminoglycan binding" MFs identified by DEGs in the lungs of both males and females (Fig. 11) also highlights and corroborates the known function role of mannose receptors as a pattern recognition receptors $[69,70]$. These endocytic/ phagocytic receptors are known to recognize patterns of carbohydrates/structural units on the surfaces and cell walls of microbial and infectious agents. Based on this, we suggest that the recognition and uptake mechanisms of CNC materials could be similar to molecules having repeating structural units such as chitin, polysaccharides or peptidoglycans commonly found in microbial cell walls and viral particles - virions. Exposure to such materials has been previously shown to induce robust inflammatory and oxidative stress responses leading to infection, asthma, COPD and other lung maladies.

As the primary target organ to airborne/inhaled materials, lungs play a major role in metabolizing such substances with the aim of reducing their potential toxicity. The metabolism of naturally occurring and/or xenobiotic organic compounds is often divided into two groups, called phase I and phase II. In this study, exposure to $\mathrm{CNC}$ materials was shown to alter the expression of both phase I and II enzymes in the lungs, albeit with differences between males and females. In phase I reactions, a variety of enzymes introduce reactive and polar groups (e.g., - $\mathrm{OH},-\mathrm{COOH},-\mathrm{SH},-\mathrm{NH} 2$ ) into their substrates by oxidation, reduction and hydrolysis reactions. Cytochrome P450 (CYP) enzymes, which catalyze hydrolysis reactions, play a critical role in defense against inhaled particles. A significant upregulation in the mRNA levels of Phase I CYP enzymes: CYP1B1 and CYP2C8 in females, and CYP2E1, CYP2A6, CYP3A7 and CYP4A14 in males was found upon exposure to $\mathrm{CNC}$ materials (Fig. 12). In addition to CYPs a significant over expression of other Phase I enzymes including AOC1 (1.35-folds) and AKR1B10 (1.36-folds). In contrast, a marked downregulation of genes related to several phase I enzymes such as many CYP family members (e.g., CYP2D9, -2B13, -2 J9, -3A7, -4 V2), ADHFE1, FMO5, ALDH1A2, and AKR1C14 was found in females (Fig. 12). The decreased expression of phase I metabolizing enzymes could be due the increased inflammatory responses found in females compared to males. Several studies reported that inflammation and/or infection can lead to downregulation of cytochrome P450s as well as other metabolizing enzymes [71-79]. Based on this, we speculate that the downregulation of phase I enzymes with the exception CYP1B1 and CYP2C8 in females is partially due to the excess production of pro-inflammatory

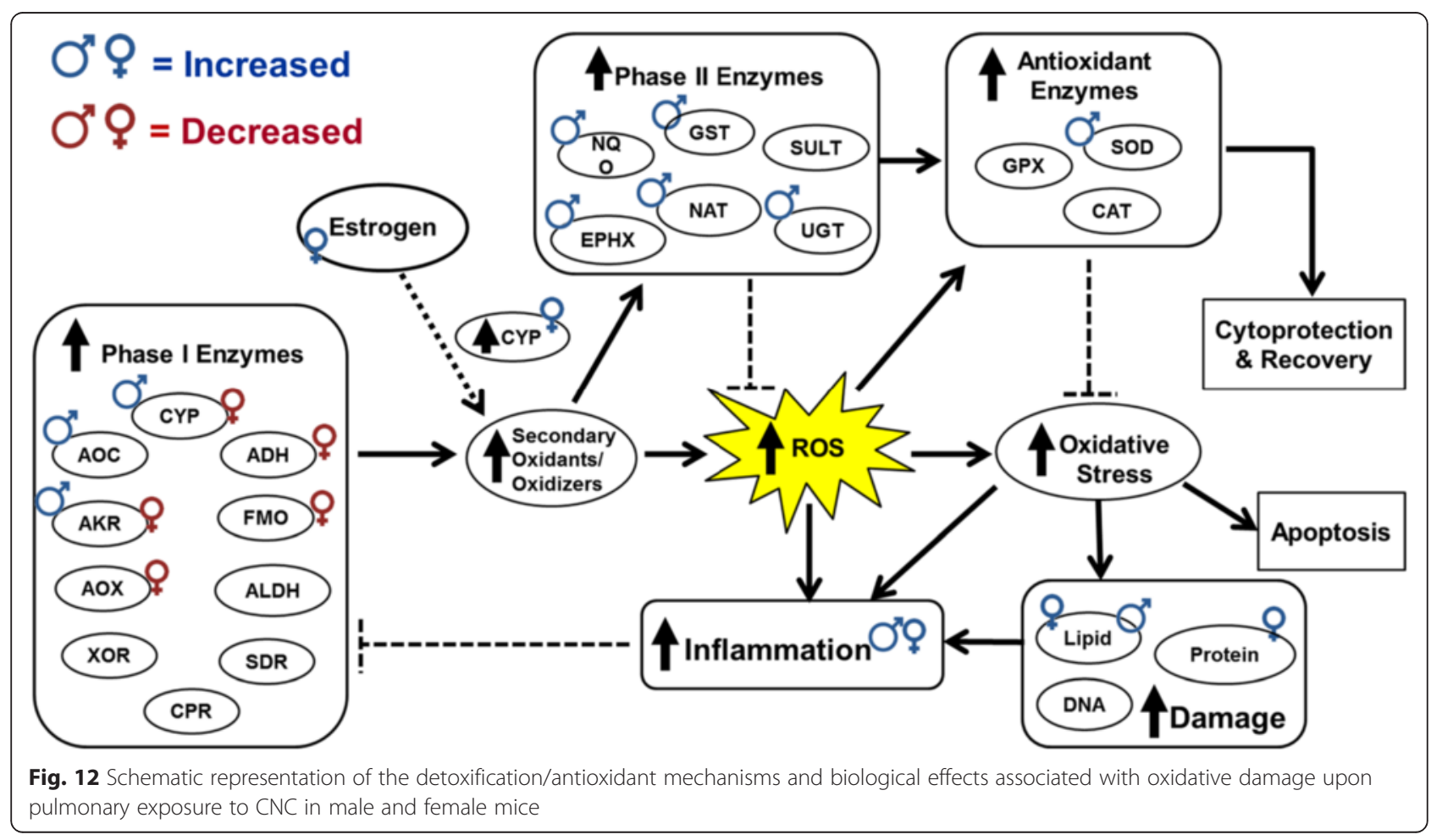


cytokines compared to males (Fig. 5 and Additional file 4: Table S2). In addition to metabolizing xenobiotic compounds and other endogenous metabolites, many CYP enzymes are also involved in catalyzing hydroxylation of estradiol. Importantly, female hormones, such as estrogen, were previously reported to regulate the expression of several CYP isoforms including CYP1B1 and CYP2C8 [80-82]. Both of these CYP isoforms were shown to directly contribute to the oxidative metabolism of estrogen - in particular estradiol metabolism. The unique GO enrichment of "aromatase activity" MF by DEGs in the females (Fig. 11), further highlights the role of female sex hormones in indirectly influencing metabolic processes that could lead to increased oxidative stress in females upon exposure to CNC (Fig. 12).

As opposed to phase I enzymes, phase II enzymes play an important role in protecting the lungs from oxidative injury, either directly or indirectly by inactivating and/or detoxifying xenobiotics and/or foreign substances. While no changes in genes related to phase II enzymes was observed in females upon exposure to $\mathrm{CNC}$, a marked increase in the mRNA levels of several phase II antioxidant/ detoxification enzymes and proteins was found in males (Fig. 12). Exposure to $\mathrm{CNC}$ in males results in significant upregulation of genes corresponding to NQO1, UGT1A6, NAT8, EPHX1, and GSTA5 (Additional file 1: File S1). Several of these enzymes have been reported to play a role in lowering toxicity associated with exposures to environmental chemicals (e.g., cigarette smoke, exhaust particulates), as well as decreasing the risk of certain types of cancer. Further the upregulation of antioxidant genes, especially GST, could also suggest an adaptive mechanism to remove CYP2E1-derived phase I oxidants in males [83-86]. As certain phase I enzymes can often convert xenobiotics to potent oxidants and oxidizers, the increased expression of CYP1B1 and CYP2C8- influenced by sex hormones - could further lead to higher levels of oxidative stress in females $[87,88]$. Thus, it seems likely that accumulation of potentially harmful secondary products (e.g., oxidants/oxidizers) either due to accelerated xenobiotic/cellulose metabolism that is influenced by estrogen or the lack of antioxidant activity and/or detoxification mechanisms could have led to increased oxidative stress responses in females than males (Fig. 12). However, it is crucial to understand whether an acute response or subchronic exposure/post-exposure to $\mathrm{CNC}$ nanomaterials is required for these gender-based differences to become apparent. Detailed in vivo inhalation studies addressing these issues and in vitro studies exploring the mechanisms of $\mathrm{CNC}$ interactions with different pulmonary cells are almost complete and/or underway. Gender has also been reported to play an important role in incidence and pathogenesis of various lung diseases [89-95]. Epidemiological and experimental data suggest that sex hormones may be important physiological modulators in the lung, and in particular, the role of estrogens in asthma has received considerable attention [89, 91, 96, 97]. Estrogens are synthesized by aromatase, a CYP enzyme located in the endoplasmic reticulum of estrogen producing cells which catalyzes the aromatization of testosterone and androstenedione to $17 \beta$-estradiol, the most active estrogen, and estrone [98]. The unique GO enrichment of "aromatase activity" MF identified by the DEGs in only CNC exposed female mice (Fig. 11B) is in line with the role of CYPs in synthesizing estrogens. Estrogens are known to preferentially up-regulate Phase I enzymes, leading to accumulation of toxic metabolites through the bio-activation. Importantly, the mRNA levels of CYP1B1, a known key Phase I enzyme in the metabolism of $17 \beta$ estradiol, was significantly elevated only in $\mathrm{CNC}$-exposed female mice along with increased estrogen in the peripheral blood (Additional file 6: Figure S1). The overexpression of CYP1B1 and estrogen in females upon exposure to $\mathrm{CNC}$ further supports the estrogen's role in regulating CYP1B1 via estrogen receptor- $\alpha(E R \alpha)$ [99]. Moreover, the mRNA levels of NCOA3, a member of the steroid receptor coactivator (SRC)/p160 family associated with ERs during transcription, was found to be up-regulated only in $\mathrm{CNC}$ exposed female mice. ERs are found on numerous immuno-regulatory cells and estrogen's actions could divert the immune response toward allergy. Additionally, it has been proposed that estrogen may act directly creating deleterious effects affecting lung mechanics and airway inflammation [93, 96, 100-102]. Several studies suggest that female sex hormones play an important role in inflammatory airway conditions [102], through different but related mechanisms. It has been shown that estrogen promotes a Th2 response, while androgen promotes a Th1 response, which may be relevant in asthma [93, 96, 101, 103-108]. The secretion of cytokines IL-4, IL-5 and IL-13 are central to orchestrating inflammatory responses by Th2 polarized cells. In fact, M2 macrophages and other phagocytic or immune cells in the BAL fluid or airway biopsies of asthmatic patients and/or allergen-challenged mice were shown to secrete a variety of inflammatory factors, including IL-4, IL-5 and IL-13 [101, 105-107]. These included factors that recruit more lymphocytes into the airways, that promote bronchoconstriction and fibrotic tissue remodeling as well as those that enhance collagen deposition for smooth-muscle thickening. A significant increase in IL-5 and IL-13 along with increased recruitment of inflammatory cells (Fig. 3), elevated levels of fibrosis markers (TGF- $\beta 1$ and collagen) (Fig. 7) and increased airway hyperresponsiveness (Fig. 7c) in females compared to males was also evident in our study. This is further corroborated by previous studies reporting females are more susceptible to the development of severe asthmatic reactions, higher 
risk of chronic obstructive pulmonary disease and lung cancer $[90,109,110]$. Taken together, these results highlight and suggest the role of CNC materials in potentially triggering Th2 dependent asthmatic responses via a sexrelated hormone, estrogen in female mice. Further studies are necessary to explore potential mechanisms involved in estrogen facilitated inflammatory outcomes observed after $\mathrm{CNC}$ exposure.

\section{Conclusion}

In conclusion, our findings clearly highlight that pulmonary exposure to respirable $\mathrm{CNC}$ materials, leading to inflammation, oxidative stress and other pulmonary responses, were more pronounced in females when compared to male mice. This study also raises the possibility of an increased risk and/or early onset of allergic responses among females upon exposure to $\mathrm{CNC}$ materials, mimicking molecules commonly found in microbial cell walls and viral particles such as chitin, polysaccharides and other peptidoglycans. Our study further suggests that the association between nanoparticle exposure and pulmonary inflammatory responses is complex and could be dependent on the type, size and structure of nanoparticles. Furthermore, these responses may be specific to the gender that is being investigated.

\section{Additional files}

Additional file 1: File S1. Differentially expressed mRNA profiles upon pharyngeal aspiration exposure to CNC. The differentially up and down-regulated mRNAs in the lungs of male and female mice 3 months after repeated pharyngeal aspiration with CNC (cumulative dose of $240 \mu \mathrm{g} /$ mouse). (XLSX $140 \mathrm{~kb}$ )

Additional file 2: Table S1. Broad groups of enriched GO_terms based on the GO_slim classification system. The Cellular Component, Biological Process and Molecular Function annotations were classified into broad groups based on the GO-slim classification system using CateGOrizer. (XLSX $18 \mathrm{~kb}$ )

Additional file 3: File S2. Enriched gene ontology terms associated with differentially expressed mRNAs in female and male mice upon exposure to CNC. The enriched Cellular Component (CC), Biological Process (BP) and Molecular Function (MF) annotations associated with the differentially expressed genes were predicted using Database for Annotation, Visualization and Integrated Discovery (DAVID) software tool. (XLSX 68 kb)

Additional file 4: Table S2. KEGG pathway enrichment analysis of up and down-regulated genes in the lungs of male and female mice exposed to CNC. (XLSX $14 \mathrm{~kb})$

Additional file 5: File S3. The list of key transcriptional factors which regulated the expression of the upregulated differentially expressed genes in males and females upon exposure to CNC. The prediction of transcription factors was performed using ChEA (ChIP Enrichment Analysis) software tool. A $P$ value cutoff of $\leq 0.05$ was considered significant in each case. (XLSX $32 \mathrm{~kb}$ )

Additional file 6: Figure S1. Levels of estrogen measured in the serum of female mice 3 month post repeated exposure with CNC (cumulative dose of $240 \mu \mathrm{g} / \mathrm{mouse}$ ). Mean \pm SEM ( $n=10 \mathrm{mice} / \mathrm{group}) .{ }^{*} p<0.05$, vs control PBS-exposed mice. (PDF $301 \mathrm{~kb}$ )

\section{Abbreviations}

CNC, cellulose nanocrystals; NC, nanocellulose; CF, cellulose fibers; BAL, bronchial alveolar lavage fluids; AFM, atomic force microscopy; DSL, dynamic light scattering analysis; SEM, scanning electron microscopy; EDX, energy dispersive X-ray spectroscopy; HEPA, high efficiency particulate air; AAALAC, Association for Assessment and Accreditation of Laboratory Animal Care; $\mathrm{NIOSH}$, National Institute of Occupational and Safety Health; OLAW, Office of Laboratory Animal Welfare; HELD, Health Effects Laboratory Division; USP, United States Pharmacopeia; OSHA, Occupational Safety \& Health Administration; FPL, Forest Products Laboratory; $\mathrm{NaOH}$, sodium hydroxide; $\mathrm{RO}$, reverse osmosis; LAL, limulus amebocyte lysate; PBS, phosphate buffered saline; AMs, alveolar macrophages; PMNs, polymorphonuclear leukocytes; $\mathrm{H}_{2} \mathrm{O}$, water; H\&E, hematoxylin and eosin; LDH, lactate dehydrogenase; MPO, myeloperoxidase; ELISA, enzyme-linked immunosorbent assay; HNE-His, hydroxynonenal protein adduct; E, estrogen; WBP, whole-body plethysmograph; MCh, methacholine; MIAME, Minimum Information About a Microarray Experiment; RTqPCR, reverse transcription quantitative polymerase chain reaction; GO, gene ontology; KEGG, Kyoto Encyclopedia of Genes and Genomes; DAVID, Database for Annotation, Visualization and Integrated Discovery; REViGO, Reduce Visualize Gene Ontology; DEGs, differentially expressed genes; ChEA, ChIP Enrichment Analysis; MGCS, multi-nucleated giant cells (MGCs); BP, biological process; MF, molecular function; CC, cellular component; APR, acute phase response; SOD, superoxide dismutase; PEL, permissible exposure limit; TWA, time weighted average; CFR, code of federal regulations; COPD, chronic obstructive pulmonary disease; CYP, cytochrome P450

\section{Acknowledgments}

The authors would like to acknowledge Ms. Lori Battelli for her technical assistance with tissue collections for histological examination.

\section{Funding}

This research was supported by NTRC $939011 \mathrm{~K}, \mathrm{NIOSH} \mathrm{OH} 008282$ and NIH R01ES019304.

\section{Availability of data and material}

The gene expression datasets supporting the conclusions are not included within the article as several mechanistic studies to fully explore/realize the complete potential of this dataset are underway.

\section{Authors' contributions}

AAS and VEK contributed to the study design and conception; ERK, NY, MTF, ALM, JSR, PMF and LPS performed the animal, biochemical, biophysical experiments or pulmonary function test and collected the data; AW and SH prepared/extracted RNA and performed microarray studies; AAS, NY, ERK, SH, AS and DWG analyzed the data and interpreted results of the different experiments employed; NY, ERK and PMF prepared figures; AAS, ERK, SH and NY performed statistical data analysis; NY performed bioinformatics analysis of the gene expression data; RSR provided cellulose nanoparticles; AAS and VEK drafted, edited and revised manuscript with contributions from NY, ERK and SH. All authors read and approved the final manuscript.

\section{Competing interests}

The authors declare that they have no competing interests.

\section{Consent for publication}

Not applicable.

\section{Ethics approval and consent to participate}

All procedures in the study comply with the ethical standards set forth by the Animal Welfare Act (enforced by the United States Department of Agriculture) and the Office of Laboratory Animal Welfare (OLAW). The studies were approved by the NIOSH Health Effects Laboratory Division (HELD) Institutional Animal Care and Use Committee within the Center for Disease Control (Public Health Services Assurance Number A4367-01) in accordance with an approved institutional animal protocol (protocol number 13-AS-M019).

\section{Disclaimer}

The findings and conclusions in this report are those of the authors and do not necessarily represent the views of the National Institute for Occupational Safety and Health.

\section{Author details}

${ }^{1}$ Health Effects Laboratory Division, NIOSH, Exposure Assessment Branch, 1095 Willowdale Road, Morgantown, WV 26505, USA. ${ }^{2}$ Engineering and 
Controls Technology Branch, NIOSH/CDC, Morgantown, WV, USA. ${ }^{3}$ Department of Physiology \& Pharmacology, School of Medicine/WVU, Morgantown, WV, USA. ${ }^{4}$ Environmental and Radiation Health Sciences Directorate, Health Canada, Ottawa, ON K1A 0 K9, Canada. ${ }^{5}$ Department of Chemistry, University of Pittsburgh, Pittsburgh, PA, USA. ${ }^{6}$ Department of Pathology, University of Pittsburgh, Pittsburgh, PA, USA. ${ }^{7}$ Forest Products Laboratory, USDA Forest Service, Madison, WI, USA. ${ }^{8}$ Free Radical Center, University of Pittsburgh, Pittsburgh, PA, USA. ${ }^{9}$ Department of Environmental \& Occupational Health, University of Pittsburgh, Pittsburgh, PA, USA.

Received: 3 March 2016 Accepted: 2 June 2016 Published online: 08 June 2016

\section{References}

1. Moon RJ, Martini A, Nairn J, Simonsen J, Youngblood J. Cellulose nanomaterials review: structure, properties and nanocomposites. Chem Soc Rev. 2011;40(7):3941-94. doi:10.1039/c0cs00108b.

2. Postek MT, Moon RJ, Rudie A, Bilodeau M. Production and Applications of Cellulose Nanomaterials. Peachtree Corners, GA: TAPPI; 2013.

3. Floros M, Hojabri L, Abraham E, Jose J, Thomas S, Pothan L, et al. Enhancement of thermal stability, strength and extensibility of lipid-based polyurethanes with cellulose-based nanofibers. Polym Degrad Stab. 2012; 97(10):1970-8. http://dx.doi.org/10.1016/j.polymdegradstab.2012.02.016.

4. H.P.S.A. K, A.H. B, A.F.I. Y. Green composites from sustainable cellulose nanofibrils: a review. Carbohyd Polym. 2012;87:963-79.

5. Siqueira G, Bras J, Dufresne A. Cellulosic bionanocomposites: a review of preparation, properties and applications. Polym. 2010;2:728-65.

6. Davis JMG. The need for standardising testing procedures for all products capable of liberating respirable fibres: the example of materials based on cellulose. Br J Ind Med. 1993;50:187-90.

7. Milton DK, Godleski JJ, Feldman HA, Greaves IA. Toxicity of intratracheally instilled cotton dust, cellulose, and endotoxin. Am Rev Respir Dis. 1990; 142(1):184-92. doi:10.1164/ajrccm/142.1.184.

8. Muhle $\mathrm{H}$, Bellmann B. Untersuchungen der Beständigkeit von Zellulosefasern in der Rattenlunge. Hannover: Fraunhofer Institut für Toxikologie und Aerosolforschung; 1995.

9. Muhle $H$, Ernst $H$, Bellmann B. Investigation of the durability of cellulose fibres in rat lungs. Ann Occup Hyg. 1997;41(Supplement 1):184-8.

10. Tatrai $\mathrm{E}$, Ungvary $\mathrm{G}$. The aetiology of experimental fibrosing alveobronchiolitis induced in rats by paprika dust. Br J Ind Med. 1992;49(7):494-8.

11. Ericsson J, Jarvholm B, Norin F. Respiratory symptoms and lung function following exposure in workers exposed to soft paper tissue dust. Int Arch Occup Environ Health. 1988;60(5):341-5.

12. Jarvholm B, Thoren $\mathrm{K}$, Brolin I, Ericsson J, Morgan U, Tylen U, et al. Lung function in workers exposed to soft paper dust. Am J Ind Med. 1988;14(4):457-64.

13. Thorén K, Järvholm B, Sällsten G, Thiringer G. Respiratory symptoms and asthma among workers exposed to paper dust: a cohort study. Am J Ind Med. 1994;26:489-96.

14. Thorén K, Sällsten G, Bake B, Drake U, Järvholm B, Sahle W. Lung function and respiratory symptoms among workers in a soft paper mill. Int Arch Occup Environ Health. 1989;61:467-71.

15. Kraus T, Pfahlberg A, Gefeller O, Raithel HJ. Respiratory symptoms and diseases among workers in the soft tissue producing industry. Occup Environ Med. 2002;59(12):830-5. doi:10.1136/oem.59.12.830.

16. Yanamala N, Farcas MT, Hatfield MK, Kisin ER, Kagan VE, Geraci CL, et al. In Vivo Evaluation of the Pulmonary Toxicity of Cellulose Nanocrystals: A Renewable and Sustainable Nanomaterial of the Future. ACS Sustain Chem Eng. 2014;2(7):1691-8. doi:10.1021/sc500153k.

17. Chen B, Kan H. Air pollution and population health: a global challenge. Environ Health Prev Med. 2008;13(2):94-101. doi:10.1007/s12199-007-0018-5.

18. Chen Y, Horne SL, Dosman JA. Increased susceptibility to lung dysfunction in female smokers. Am Rev Respir Dis. 1991;143(6):1224-30. doi:10.1164/ ajrccm/143.6.1224.

19. Comstock GW, Meyer MB, Helsing KJ, Tockman MS. Respiratory effects on household exposures to tobacco smoke and gas cooking. Am Rev Respir Dis. 1981;124(2):143-8.

20. Kauffmann F, Becklake M. Maladies obstructives pulmonaires: un paradigme de la complexité des differences de santé entre hommes et femmes. In: Saurel-Cubizolles MJ BB, editor. La santé des femmes. Paris: Flammarion, Medecine et Sciences; 1996. p. 209-33.

21. Schwab R. Sex differences and sleep apnea. Thorax. 1999;54:284-5.
22. Thom TJ. International comparisons in COPD mortality. Am Rev Respir Dis. 1989;140(3 Pt 2):S27-34. doi:10.1164/ajrccm/140.3_Pt_2.S27.

23. Weinmann GG, Weidenbach-Gerbase M, Foster WM, Zacur H, Frank R. Evidence for ozone-induced small-airway dysfunction: lack of menstrual-cycle and gender effects. Am J Respir Crit Care Med. 1995;152(3):988-96. doi:10. 1164/ajrccm.152.3.7663815.

24. Yanamala N, Hatfield MK, Farcas MT, Schwegler-Berry D, Hummer JA, Shurin $M R$, et al. Biodiesel versus diesel exposure: enhanced pulmonary inflammation, oxidative stress, and differential morphological changes in the mouse lung. Toxicol Appl Pharmacol. 2013;272(2):373-83. doi:10.1016/j.taap.2013.07.006

25. Stone KC, Mercer RR, Freeman BA, Chang LY, Crapo JD. Distribution of lung cell numbers and volumes between alveolar and nonalveolar tissue. Am Rev Respir Dis. 1992;146(2):454-6. doi:10.1164/ajrccm/146.2.454.

26. Mercer RR, Scabilloni J, Wang L, Kisin E, Murray AR, Schwegler-Berry D, et al. Alteration of deposition pattern and pulmonary response as a result of improved dispersion of aspirated single-walled carbon nanotubes in a mouse model. Am J Physiol Lung Cell Mol Physiol. 2008;294(1):L87-97. doi: 10.1152/ajplung.00186.2007.

27. ICRP. Human Respiratory Tract Model for Radiological Protection. Ann. ICRP 1994

28. Reiner RS, Rudie AW. Process scale-up of cellulose nanocrystal production to $25 \mathrm{~kg}$ per batch at the forest products laboratory. Production and Applications of Cellulose Nanomaterials. Peachtree Corners, GA: TAPPI Press; 2013.

29. Rao GV, Tinkle S, Weissman DN, Antonini JM, Kashon ML, Salmen R, et al. Efficacy of a technique for exposing the mouse lung to particles aspirated from the pharynx. J Toxicol Environ Health A. 2003;66(15):1441-52. doi:10. 1080/15287390306417

30. Lang JK, Gohil K, Packer L. Simultaneous determination of tocopherols, ubiquinols, and ubiquinones in blood, plasma, tissue homogenates, and subcellular fractions. Anal Biochem. 1986;157(1):106-16.

31. Kerr MK, Churchill GA. Statistical design and the analysis of gene expression microarray data. Genet Res. 2007;89(5-6):509-14. doi:10.1017/S0016672308009713.

32. Kerr MK, Churchill GA. Statistical design and the analysis of gene expression microarray data. Genet Res. 2001;77(2):123-8.

33. Kerr MK. Design considerations for efficient and effective microarray studies Biometrics. 2003;59(4):822-8.

34. Team RC. R: A language and environment for statistical computing. Vienna, Austria: R Foundation for Statistical Computing; 2015.

35. Yang YH, Dudoit S, Luu P, Lin DM, Peng V, Ngai J, et al. Normalization for CDNA microarray data: a robust composite method addressing single and multiple slide systematic variation. Nucleic Acids Res. 2002;30(4):e15.

36. Wu H, Kerr MK, Cui X, Churchill G. MAANOVA: A Software Package for the Analysis of Spotted cDNA Microarray Experiments. In: Parmigiani G, Garrett E, Irizarry R, Zeger S, editors. The Analysis of Gene Expression Data. Statistics for Biology and Health. New York: Springer; 2003. p. 313-41.

37. Cui X, Hwang JT, Qiu J, Blades NJ, Churchill GA. Improved statistical tests for differential gene expression by shrinking variance components estimates. Biostatistics. 2005:6(1):59-75. doi:10.1093/biostatistics/kxh018.

38. Goodnight $\mathrm{JH}$, Harvey WR. Least-Squares Means in the Fixed-Effects General Linear Models. Cary, NC1978 Contract No:: SAS Technical Report R-103.

39. Searle SR, Speed FM, Milliken GA. Population Marginal Means in the Linear Model: An Alternative to Least Squares Means. Am Stat. 1980;34(4):216-21. doi:10.2307/2684063

40. da Huang W, Sherman BT, Lempicki RA. Systematic and integrative analysis of large gene lists using DAVID bioinformatics resources. Nat Protoc. 2009; 4(1):44-57. doi:10.1038/nprot.2008.211.

41. Huang da W, Sherman BT, Zheng X, Yang J, Imamichi T, Stephens R et al. Extracting biological meaning from large gene lists with DAVID. Current protocols in bioinformatics/editoral board, Andreas D Baxevanis [et al]. 2009; Chapter 13:Unit 13 1. doi:10.1002/0471250953.bi1311s27.

42. Hu Zhi-Liang BJaRJ. CateGOrizer: A Web-Based Program to Batch Analyze Gene Ontology Classification Categories. Online J Bioinform. 2008;9(2):108-12.

43. Supek F, Bosnjak M, Skunca N, Smuc T. REVIGO summarizes and visualizes long lists of gene ontology terms. PLoS One. 2011;6(7):e21800. doi:10.1371/ journal.pone.0021800.

44. Lachmann A, Xu H, Krishnan J, Berger SI, Mazloom AR, Ma'ayan A. ChEA: transcription factor regulation inferred from integrating genome-wide ChIP-X experiments. Bioinformatics. 2010;26(19):2438-44. doi:10.1093/ bioinformatics/bta466.

45. McNally AK, Anderson JM. Macrophage fusion and multinucleated giant cells of inflammation. Adv Exp Med Biol. 2011;713:97-111. doi:10.1007/ 978-94-007-0763-4_7. 
46. Tatrai E, Brozik M, Adamis Z, Meretey K, Ungvary G. In vivo pulmonary toxicity of cellulose in rats. J Appl Toxicol. 1996;16(2):129-35. doi:10.1002/ (SICI)1099-1263(199603)16:2<129::AID-JAT316>3.0.CO;2-C.

47. Adamis Z, Tatrai E, Honma K, Ungvary G. In vitro and in vivo assessment of the pulmonary toxicity of cellulose. J Appl Toxicol. 1997;17(2):137-41.

48. Hadley J, Kotin P, Bernstein D, editors. Sub-acute (28 days) repeated dose inhalation toxicity of cellulose building insulation in the rat. US Society of Toxicology Conference, Seattle, 11th February; 1992.

49. KF M, A E, A R, C. G. Occupational exposure characterization during the manufacture of cellulose nanomaterials. Production and applications of cellulose nanomaterials. Peachtree Corners, GA: TAPPI Press; 2013.

50. Vartiainen J, Pöhler T, Sirola K, et al. Health and environmental safety aspects of friction grinding and spray drying of microfibrillated cellulose. Cellulose. 2011;18:775-86.

51. Kobayashi H, Kanoh S, Motoyoshi K, Aida S. Diffuse lung disease caused by cotton fibre inhalation but distinct from byssinosis. Thorax. 2004;59(12): 1095-7. doi:10.1136/thx.2003.014027.

52. Greim H, Borm P, Schins R, Donaldson K, Driscoll K, Hartwig A, et al. Toxicity of fibers and particles. Report of the workshop held in Munich, Germany, 26-27 October 2000. Inhal Toxicol. 2001;13(9):737-54. doi:10.1080/ 08958370118273.

53. Coplu L, Demir AU, Fuat Kalyoncu A, Coplu N, Selcuk ZT, Enunlu T, et al. Lung health in workers exposed to reed dust. Respir Med. 2005;99(4):421-8. doi:10.1016/j.rmed.2004.08.015.

54. Kraus T, Pfahlberg A, Zobelein P, Gefeller O, Raithel HJ. Lung function among workers in the soft tissue paper-producing industry. Chest. 2004; 125(2):731-6.

55. Stefaniak AB, Seehra MS, Fix NR, Leonard SS. Lung biodurability and free radical production of cellulose nanomaterials. Inhal Toxicol. 2014;26(12):733-49. doi:10.3109/08958378.2014.948650.

56. CFR. Code of Federal Regulations. Washington, DC: U.S. Government Printing Office, Office of the Federal Register.

57. Bates DV, Fish BR, Hatch TF, Mercer TT, Morrow PE. Deposition and retention models for internal dosimetry of the human respiratory tract. Task group on lung dynamics. Health Phys. 1966;12(2):173-207.

58. [1992] N. Recommendations for occupational safety and health: Compendium of policy documents and statements. In: U.S. Department of Health and Human Services PHS, Centers for Disease Control, National Institute for Occupational Safety and Health" editor. Cincinnati, OH: DHHS (NIOSH); 1992.

59. An J, Ribeiro RC, Webb P, Gustafsson JA, Kushner PJ, Baxter JD, et al. Estradiol repression of tumor necrosis factor-alpha transcription requires estrogen receptor activation function-2 and is enhanced by coactivators. Proc Natl Acad Sci U S A. 1999;96(26):15161-6.

60. Hu SK, Mitcho YL, Rath NC. Effect of estradiol on interleukin 1 synthesis by macrophages. Int J Immunopharmacol. 1988;10(3):247-52.

61. Kahlke V, Angele MK, Ayala A, Schwacha MG, Cioffi WG, Bland Kl, et al. Immune dysfunction following trauma-haemorrhage: influence of gender and age. Cytokine. 2000;12(1):69-77. doi:10.1006/cyto.1999.0511.

62. Wichmann MW, Zellweger R, DeMaso CM, Ayala A, Chaudry IH. Enhanced immune responses in females, as opposed to decreased responses in males following haemorrhagic shock and resuscitation. Cytokine. 1996;8(11):853-63. doi:10.1006/cyto.1996.0114.

63. Kurimoto E, Miyahara N, Kanehiro A, Waseda K, Taniguchi A, Ikeda G, et al. $\mathrm{IL}-17 \mathrm{~A}$ is essential to the development of elastase-induced pulmonary inflammation and emphysema in mice. Respir Res. 2013;14:5. doi:10.1186/ 1465-9921-14-5.

64. Kang MJ, Choi JM, Kim BH, Lee CM, Cho WK, Choe G, et al. IL-18 induces emphysema and airway and vascular remodeling via IFN-gamma, IL-17A and IL-13. Am J Respir Crit Care Med. 2012;185(11):1205-17. doi:10.1164/ rccm.201108-15450C.

65. Tanaka J, Moriyama H, Terada M, Takada T, Suzuki E, Narita I, et al. An observational study of giant cell interstitial pneumonia and lung fibrosis in hard metal lung disease. BMJ Open. 2014;4(3):e004407. doi:10.1136/ bmjopen-2013-004407.

66. Quinn MT, Schepetkin IA. Role of NADPH oxidase in formation and function of multinucleated giant cells. J Innate Immun. 2009;1(6):509-26. doi:10. $1159 / 000228158$.

67. DeFife KM, Jenney CR, McNally AK, Colton E, Anderson JM. Interleukin-13 induces human monocyte/macrophage fusion and macrophage mannose receptor expression. J Immunol. 1997;158(7):3385-90.
68. MCNally AK, DeFife KM, Anderson JM. Interleukin-4-induced macrophage fusion is prevented by inhibitors of mannose receptor activity. Am J Pathol. 1996;149(3):975-85.

69. Linehan SA, Martinez-Pomares L, Gordon S. Mannose receptor and scavenger receptor: two macrophage pattern recognition receptors with diverse functions in tissue homeostasis and host defense. Adv Exp Med Biol. 2000;479:1-14. doi:10.1007/0-306-46831-x_1.

70. Stahl PD, Ezekowitz RA. The mannose receptor is a pattern recognition receptor involved in host defense. Curr Opin Immunol. 1998;10(1):50-5.

71. Bleau AM, Maurel P, Pichette V, Leblond F, du Souich P. Interleukin-1 beta, interleukin-6, tumour necrosis factor-alpha and interferon-gamma released by a viral infection and an aseptic inflammation reduce CYP1A1, 1A2 and 3A6 expression in rabbit hepatocytes. Eur J Pharmacol. 2003:473(2-3):197-206.

72. Renton KW. Cytochrome P450 regulation and drug biotransformation during inflammation and infection. Curr Drug Metab. 2004;5(3):235-43.

73. Renton KW. Regulation of drug metabolism and disposition during inflammation and infection. Expert Opin Drug Metab Toxicol. 2005;1(4):629-40. doi:10.1517/17425255.1.4.629.

74. Aitken AE, Morgan ET. Gene-specific effects of inflammatory cytokines on cytochrome P450 2C, 2 B6 and 3A4 mRNA levels in human hepatocytes. Drug Metab Dispos. 2007;35(9):1687-93. doi:10.1124/dmd.107.015511.

75. Teng S, Piquette-Miller M. Regulation of transporters by nuclear hormone receptors: implications during inflammation. Mol Pharm. 2008;5(1):67-76. doi:10.1021/mp700102q.

76. Siewert E, Bort R, Kluge R, Heinrich PC, Castell J, Jover R. Hepatic cytochrome P450 down-regulation during aseptic inflammation in the mouse is interleukin 6 dependent. Hepatology. 2000;32(1):49-55. doi:10. 1053/jhep.2000.8532

77. Warren GW, van Ess PJ, Watson AM, Mattson MP, Blouin RA. Cytochrome P450 and antioxidant activity in interleukin-6 knockout mice after induction of the acute-phase response. J Interferon Cytokine Res. 2001;21(10):821-6. doi:10.1089/107999001753238060.

78. Sewer MB, Koop DR, Morgan ET. Differential inductive and suppressive effects of endotoxin and particulate irritants on hepatic and renal cytochrome P-450 expression. J Pharmacol Exp Ther. 1997;280(3):1445-54.

79. Morgan ET. Regulation of cytochromes P450 during inflammation and infection. Drug Metab Rev. 1997;29(4):1129-88. doi:10.3109/03602539709002246.

80. Lee AJ, Cai MX, Thomas PE, Conney AH, Zhu BT. Characterization of the oxidative metabolites of 17 beta-estradiol and estrone formed by 15 selectively expressed human cytochrome p450 isoforms. Endocrinology. 2003;144(8):3382-98. doi:10.1210/en.2003-0192.

81. Hayes CL, Spink DC, Spink BC, Cao JQ, Walker NJ, Sutter TR. 17 beta-estradiol hydroxylation catalyzed by human cytochrome P450 1B1. Proc Natl Acad Sci U S A. 1996;93(18):9776-81.

82. Badawi AF, Cavalieri EL, Rogan EG. Role of human cytochrome P450 1A1, $1 \mathrm{~A} 2,1 \mathrm{B1}$, and $3 \mathrm{~A} 4$ in the 2-, 4-, and 16alpha-hydroxylation of 17betaestradiol. Metab Clin Exp. 2001;50(9):1001-3. doi:10.1053/meta.2001.25592.

83. Leung TM, Nieto N. CYP2E1 and oxidant stress in alcoholic and nonalcoholic fatty liver disease. J Hepatol. 2013;58(2):395-8. doi:10.1016/j.jhep. 2012.08.018

84. Lu Y, Cederbaum Al. CYP2E1 and oxidative liver injury by alcohol. Free Radic Biol Med. 2008;44(5):723-38. doi:10.1016/j.freeradbiomed.2007.11.004.

85. Cederbaum Al. Nrf2 and antioxidant defense against CYP2E1 toxicity. Subcell Biochem. 2013;67:105-30. doi:10.1007/978-94-007-5881-0_2.

86. Cederbaum A. Nrf2 and antioxidant defense against CYP2E1 toxicity. Expert Opin Drug Metab Toxicol. 2009;5(10):1223-44. doi:10.1517/ 17425250903143769

87. Prestera T, Holtzclaw WD, Zhang Y, Talalay P. Chemical and molecular regulation of enzymes that detoxify carcinogens. Proc Natl Acad Sci U S A. 1993:90(7):2965-9.

88. Prestera T, Zhang Y, Spencer SR, Wilczak CA, Talalay P. The electrophile counterattack response: protection against neoplasia and toxicity. Adv Enzym Regul. 1993;33:281-96.

89. Almqvist C, Worm M, Leynaert B, working group of GALENWPG. Impact of gender on asthma in childhood and adolescence: a GA2LEN review. Allergy. 2008;63(1):47-57. doi:10.1111/j.1398-9995.2007.01524.x.

90. Caracta CF. Gender differences in pulmonary disease. Mt Sinai J Med. 2003; 70(4):215-24.

91. Fagan JK, Scheff PA, Hryhorczuk D, Ramakrishnan V, Ross M, Persky V. Prevalence of asthma and other allergic diseases in an adolescent population: association with gender and race. Ann Allergy Asthma Immunol. 2001;86(2):177-84. doi:10.1016/\$1081-1206(10)62688-9. 
92. Oiamo TH, Luginaah IN. Extricating sex and gender in air pollution research: a community-based study on cardinal symptoms of exposure. Int J Environ Res Public Health. 2013;10(9):3801-17. doi:10.3390/ijerph10093801.

93. Riffo-Vasquez Y, Ligeiro de Oliveira AP, Page CP, Spina D, Tavares-de-Lima W. Role of sex hormones in allergic inflammation in mice. Clin Exp Allergy. 2007;37(3):459-70. doi:10.1111/j.1365-2222.2007.02670.x.

94. Casimir GJ, Lefevre N, Corazza F, Duchateau J. Sex and inflammation in respiratory diseases: a clinical viewpoint. Biol Sex Differ. 2013;4:16. doi:10. 1186/2042-6410-4-16.

95. Morrissey BM, Harper RW. Bronchiectasis: sex and gender considerations. Clin Chest Med. 2004;25(2):361-72. doi:10.1016/j.ccm.2004.01.011.

96. Bonds RS, Midoro-Horiuti T. Estrogen effects in allergy and asthma. Curr Opin Allergy Clin Immunol. 2013;13(1):92-9. doi:10.1097/ACl. 0b013e32835a6dd6.

97. Haggerty $\mathrm{CL}$, Ness RB, Kelsey S, Waterer GW. The impact of estrogen and progesterone on asthma. Ann Allergy Asthma Immunol. 2003;90(3):284-91. doi:10.1016/S1081-1206(10)61794-2. quiz 91-3, 347.

98. Simpson ER, Clyne C, Rubin G, Boon WC, Robertson K, Britt K, et al. Aromatase-a brief overview. Annu Rev Physiol. 2002;64:93-127. doi:10.1146/annurev.physiol.64.081601.142703.

99. Tsuchiya Y, Nakajima M, Kyo S, Kanaya T, Inoue M, Yokoi T. Human CYP1B1 is regulated by estradiol via estrogen receptor. Cancer Res. 2004:64(9):3119-25.

100. Tam A, Morrish D, Wadsworth S, Dorscheid D, Man SF, Sin DD. The role of female hormones on lung function in chronic lung diseases. BMC Womens Health. 2011;11:24. doi:10.1186/1472-6874-11-24.

101. Keselman A, Heller NM. Estrogen signaling modulates allergic inflammation and contributes to sex differences in asthma. Front Immunol. 2015;6. doi:10. 3389/fimmu.2015.00568.

102. Cutolo M, Sulli A, Straub RH. Estrogen's effects in chronic autoimmune/ inflammatory diseases and progression to cancer. Expert Rev Clin Immunol. 2014;10(1):31-9. doi:10.1586/1744666X.2014.863149.

103. Cai Y, Zhou J, Webb DC. Estrogen stimulates Th2 cytokine production and regulates the compartmentalisation of eosinophils during allergen challenge in a mouse model of asthma. Int Arch Allergy Immunol. 2012; 158(3):252-60. doi:10.1159/000331437.

104. Carey MA, Card JW, Voltz JW, Germolec DR, Korach KS, Zeldin DC. The impact of sex and sex hormones on lung physiology and disease: lessons from animal studies. Am J Physiol Lung Cell Mol Physiol. 2007;293(2):L272-8. doi:10.1152/ajplung.00174.2007.

105. Robbe P, Draijer C, Borg TR, Luinge M, Timens W, Wouters IM, et al. Distinct macrophage phenotypes in allergic and nonallergic lung inflammation. Am J Physiol Lung Cell Mol Physiol. 2015;308(4):L358-67. doi:10.1152/ajplung. 00341.2014 .

106. Bousquet J, Chanez P, Lacoste JY, Barneon G, Ghavanian N, Enander I, et al. Eosinophilic inflammation in asthma. N Engl J Med. 1990;323(15):1033-9. doi:10.1056/NEJM199010113231505.

107. Liu YC, Zou XB, Chai YF, Yao YM. Macrophage polarization in inflammatory diseases. Int J Biol Sci. 2014;10(5):520-9. doi:10.7150/ijbs.8879.

108. Labonte AC, Tosello-Trampont AC, Hahn YS. The role of macrophage polarization in infectious and inflammatory diseases. Mol Cells. 2014;37(4): 275-85. doi:10.14348/molcells.2014.2374.

109. Clougherty JE, Eisen EA, Slade MD, Kawachi I, Cullen MR. Gender and sex differences in job status and hypertension. Occup Environ Med. 2011;68(1): 16-23. doi:10.1136/oem.2009.049908.

110. Clougherty JE. A growing role for gender analysis in air pollution epidemiology. Environ Health Perspect. 2010;118(2):167-76. doi:10.1289/ehp.0900994.

\section{Submit your next manuscript to BioMed Central and we will help you at every step:}

- We accept pre-submission inquiries

- Our selector tool helps you to find the most relevant journal

- We provide round the clock customer support

- Convenient online submission

- Thorough peer review

- Inclusion in PubMed and all major indexing services

- Maximum visibility for your research

Submit your manuscript at www.biomedcentral.com/submit
Biomed Central 